\title{
FINITE DIFFERENCE PROGRAM FOR CALCULATING HYDRIDE BED WALL TEMPERATURE PROFILES (U)
}

by J. E. Klein

Westinghouse Savannah River Company

Savannah River Site

Aiken, South Carolina 29808

Other Authors:

This paper was prepared in connection with work done under Contract No. DE-AC09-89SR18035 with the U. S. Department of Energy. By acceptance of this paper, the publisher and/or recipient acknowledges the U. S. Government's right to retain a nonexclusive, royalty-free license in and to any copyright covering this paper, along with the right to reproduce and to authorize others to reproduce all or part of the copyrighted paper. 


\section{DISCLAIMER}

This report was prepared as an account of work sponsored by an agency of the United States Government. Neither the United States Government nor any agency thereof, nor any of their employees, makes any warranty, express or implied, or assumes any legal liability or responsibility for the accuracy, completeness, or usefulness of any information, apparatus, product, or process disclosed, or represents that its use would not infringe privately owned rights. Reference herein to any specific commercial product, process, or service by trade name, trademark, manufacturer, or otherwise does not necessarily constitute or imply its endorsement, recommendation, or favoring by the United States Government or any agency thereof. The views and opinions of authors expressed herein do not necessarily state or reflect those of the United States Government or any agency thereof.

This report has been reproduced directly from the best available copy.

Available to DOE and DOE contractors from the Office of Scientific and Technical Information, P. O. Box 62, Oak Ridge, TN 37831; prices available _.m (615) $576-8401$.

Available to the public from the National Technical Information Service, U. S. Department of Commerce, 5285 Port Royal Rd., Springfield, VA 22161.

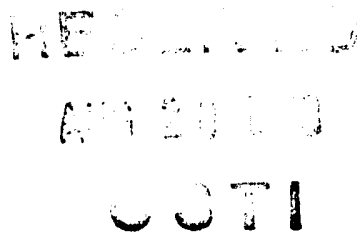




\begin{abstract}
To: J.R. Knight, 773-A
From: J.E. Klein, 773-A 2CK

FINITE DIFFEREACE PROGRAM FOR CALCOLATING HYDRIDE BED WALL TEMPERATURE PROFILES (U)
\end{abstract}

GUMQARY

A QuickBASIC finite difference program was written for calculating one dimensional temperature profiles in up to two media with flat, cylindrical, or spherical geometries. The development of the program was motivated by the need to calculate maximum temperature differences across the walls of the Tritium metal hydrides beds for thermal fatigue analysis.

\title{
INTRODUCTION
}

This purpose of this report is to document the equations and the computer program used to caiculate transient wall temperatures in stainless steel hydride vessels. The development of the computer code was motivated by the need to calculate maximum temperature differences across the walls of the hydrides beds in the Tritium Facility for thermal fatigua analysis.

A QuickBASIC finite difference program was written for calculating one dimensional temperature profiles in up to two media with flat, cylindrical, or spherical geometries. The two materials in contact with one another may have concentric geometries (e.g. a cylinder in a cylinder) or contacting geometries (e.g. a cylinder in contact with a sphere). This program was written so analysis on systems other than the hydride beds may be performed.

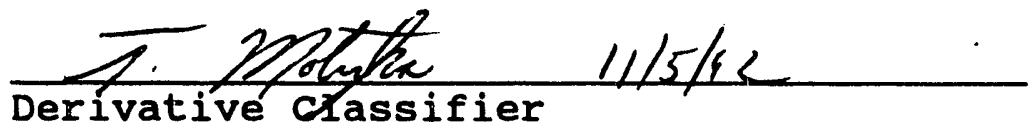




\section{DI8CU88ION}

\section{Heat Conduction Difference Equations}

Heat conduction equation for material "i", with constant thermal conductivity, $k_{i}$,

$$
\rho_{i} C_{p i} \frac{\partial T_{i}}{\partial t}=k_{i} \nabla^{2} T=k_{i}\left[\frac{\partial^{2} T_{i}}{\partial r_{i}^{2}}+\frac{\Omega_{i}}{r_{i}} \frac{\partial T_{i}}{\partial r_{i}}\right]
$$

where $\Omega_{i}=0,1$, or 2 for planar, cylindrical, or spherical geometries, respectively.

For finite difference approximations, let $T_{i, j}{ }^{n}$ be the temperature of material $i$, at the $j$ th spacial node and nth time step for $j=0, \ldots, M_{i}$ and $n=0, \ldots, N$. The following finite difference approximations were used to approximate the derivatives:

$$
\begin{gathered}
\frac{\partial T_{i}}{\partial t} \approx \frac{T_{i, j}^{n+1}-T_{i, j}^{n}}{\Delta t} \\
\frac{\partial T_{i}}{\partial r_{i}} \approx \frac{T_{i, j+1}^{n}-T_{i, j-1}^{n}}{2 \Delta r_{i}} \\
\frac{\partial^{2} T_{i}}{\partial r_{i}^{2}} \approx \frac{T_{i, j-1}^{n}-2 T_{i, j}^{n}+T_{i, j+1}^{n}}{\left(\Delta r_{i}\right)^{2}}
\end{gathered}
$$

Using the Crank-Nicolson method with these finite difference expressions, the differential equation becomes

$$
\begin{aligned}
& {\left[-\gamma_{i}+\delta_{i}\right] T_{i, j-1}^{n+1}+\left[2+2 \gamma_{i}\right] T_{i, j}^{n+1}+\left[-\gamma_{i}-\delta_{i}\right] T_{i, j+1}^{n+1}} \\
& =\left[\gamma_{i}-\delta_{i}\right] T_{i, j-1}^{n}+\left[2-2 \gamma_{i}\right] T_{i, j}^{n}+\left[\gamma_{i}+\delta_{i}\right] T_{i, j+1}^{n}
\end{aligned}
$$

where

$$
\alpha_{i}=\frac{k_{i}}{\rho_{i} C_{p i}}, \quad \gamma=\frac{\alpha_{i} \Delta t}{\left(\Delta r_{i}\right)^{2}}, \quad \delta_{i}=\frac{\alpha_{i} \Delta t \boldsymbol{\Omega}_{i}}{2 I_{i} \Delta I_{i}}
$$


At the internal boundary $(j=0)$, the boundary condition is given by

$$
-k_{i} \frac{\partial T_{i}}{\partial r_{i}}+h_{i, \text { in }} T_{i}=f_{i, \text { in, }} \text { at } r_{i}=I_{i, \text { in }}
$$

and at the external boundary, $\left(j=M_{i}, r_{i, e x}>r_{i, i n}\right)$, the boundary condition is given by

$$
k_{i} \frac{\partial T_{i}}{\partial r_{i}}+h_{i, \theta x} T_{i}=f_{1, \theta x^{\prime}} \text { at } r_{1}=r_{1, \theta x}
$$

where $f_{i, b}$ is the heat transfer function at the boundary of material i. For constant, convective heat loss, $f_{i, b}=h_{i, b} T_{\infty b}$ where $T_{\infty b}$ is the bulk temperature for convective heat transport.

To satisfy the finite difference equation at the boundaries, fictitious temperature values $T_{i,-1}$ and $T_{i, M i+1}$ where defined. Usirig the boundary condition at $r_{i}=r_{i, i n}$,

$$
T_{i,-1}^{n}=\frac{-2 \Delta r_{i} h_{i, i n}}{k_{i}} T_{i, 0}^{n}+T_{i, 1}^{n}+\frac{2 \Delta r_{i}}{k_{i}} f_{i, i n}^{n}
$$

Similarly, using the boundary condition at $r_{i}=r_{i, e x}$ :

$$
T_{i, M+1}^{n}=T_{i, M-?}^{n}+\frac{-2 \Delta r_{i} h_{i, \theta x}}{k_{i}} T_{i, M_{i}}^{n}+\frac{2 \Delta r_{i}}{k_{i}} f_{i, \theta x}^{n}
$$

\section{Matrix system for a single Material}

\section{System of Equations}

The finite difference expression and these boundary conditions form the following system of equations:

$$
A T^{n+1}=B T^{n}+C=D
$$

where 


$$
\boldsymbol{A}=\left[\begin{array}{cccccc}
2+2 \gamma_{i} \beta_{1, \text { in }}-2 \delta_{1} \lambda_{i, \text { in }} & -2 \gamma_{i} & 0 & \cdots & 0 & 0 \\
-\gamma_{i}+\delta_{i} & 2+2 \gamma_{i} & -\gamma_{i}-\delta_{i} & \cdots & 0 & 0 \\
\cdot & \cdot & \cdot & \cdot & \cdot & . \\
\cdot & \cdot & \cdot & \cdot & \cdot & . \\
\cdot & \cdot & \cdot & \cdot & \cdot & \cdot \\
0 & 0 & \cdots & -\gamma_{i}+\delta_{i} & 2+2 \gamma_{i} & -\gamma_{i}-\delta_{i} \\
0 & 0 & \cdots & 0 & -2 \gamma_{i} 2+2 \gamma_{i} \beta_{i, \theta x}+2 \delta_{i} \lambda_{i, \theta x}
\end{array}\right]
$$

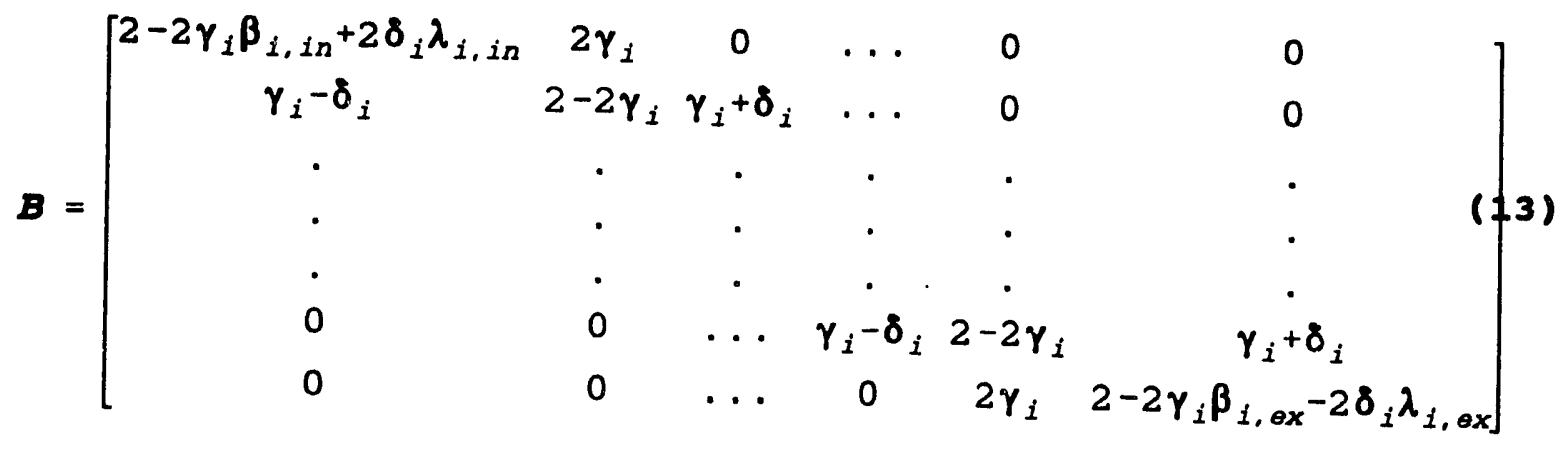

$$
T^{D+1}=\left[\begin{array}{c}
T_{i, 0}^{n+1} \\
T_{i, 1}^{n+1} \\
\cdot \\
\cdot \\
\cdot \\
T_{i, M_{1}-1}^{n+1} \\
T_{i, M_{1}}^{n+1}
\end{array}\right], \quad T^{\mathbf{n}}=\left[\begin{array}{c}
T_{i, 0}^{n} \\
T_{i, 1}^{n} \\
\cdot \\
\cdot \\
\cdot \\
T_{i, M_{1}-1}^{n} \\
T_{i, M_{1}}^{n}
\end{array}\right], \quad C=\left[\begin{array}{c}
4\left(\gamma_{i}-\delta_{i}\right) \mu_{i, i n} \\
0 \\
\cdot \\
\cdot \\
\cdot \\
0 \\
4\left(\gamma_{i}+\delta_{i}\right) \mu_{i, \text { ox }}
\end{array}\right]
$$

The system of equations are solved as follows. At time zero $(n=0)$, the initial temperature distribution in the material is known, $T^{n},(n=0)$ so vector $D$ can be calculated using $\mathbf{D}=\mathbf{B} T^{\mathbf{n}}+\mathbf{C}$. The temperature at the next time step, $\mathbf{T}^{\mathbf{n}+1}$, is obtained by solving the system of equation $A T^{n+1}=D$. These steps are repeated for each.time step. The matrix system is similar to that derived by özişik ${ }^{1}$ for a rectangular geometry. 


\section{System Modifications for Different Boundary Conditions}

Seven different boundary conditions can be applied at each interior and each exterior boundary. These options and how they affect the system of equations to solve are discussed below.

\section{Case 1. Constant surface Temperature}

For a constant internal surface temperature at $r_{i}=r_{i, i n}$, element $a_{0,0}$ is set equal to 1 and $a_{0,1}$ is set equal to $0, b_{0,0}$ is set equal to 1 and $b_{0,1}$ is set equal to 0 , and $c_{0}=0$. similarly for $a$ constant external surface temperature at $r_{i}=r_{i, e x}$, element $a_{M i, M-1 i}$ is set equal to 1 and $a_{M i, M i}$ is set equal to $0, b_{M i, M-1 i}$ is set equal to 0 and $b_{M i, M i}$ is set equal to 1 , and $c_{M i}=0$. The surface

temperatures are set to their respective values at time $=0$ and are constant throughout the computation.

\section{Case 2. Perfectly Insulated Boundary}

For a perfectly insulated surface, the terms $h_{i, b}$ and $f_{i, b}$ are set to zero. This gives $\lambda_{i, b}=0, \beta_{i, b}=1$, and $\mu_{i, b}=0$ for the appropriate boundary.

\section{Case 3. Constant Boundary Heat Flux}

For a constant heat (energy) flux at a boundary, $h_{i, b}$ is set to zero. The term $f_{i, b}$ is set to a positive value for energy going into the material and to a negative value for energy leaving the material.

\section{Case 4. Constant Convective Heat Flux}

For a constant convective heat flux at a boundary, $f_{i, b}$ is set equal to $h_{i, b} T_{\infty, b}$. This gives the familiar convective heat loss expression which can be seen by examining the boundary conditions. 
Case 5. Variable surface Temperature

For a surface temperatures as a function of time, the matrix elements of $A$ and $B$ are modified as was done in the case for $a$ constant surface temperature (case 1 ). Instead of a surface temperatures being constant, the surface temperature as a function of time is entered into a subroutine of the program and the temperature values updated at each time step.

\section{Case 6. Variable Surface Heat Flux}

Parameters for the system are treated as they were for the case of constant heat flux for a surface. In this case, $f_{i, b}$ is a function of time, positive for energy going into the material, negative value for energy leaving the material, and is updated at each time step.

\section{Case 7. Variable Convective Heat Flux}

For a variable convective heat flux at a boundary, $f_{i, b}$ is set equal to $h_{i, b} T_{\infty, b}$, where $T_{\infty, b}$ is a function of time. The value of $\mathrm{T}_{\infty, b}$ is updated at each time step.

\section{Matrix systems for Composite (Two) Materials}

\section{Equations for Concentric Geometries}

For two concentric geometries, such as cylinder 1 inside and in thermal contact with cylinder 2 , the boundary condition is

$$
-k_{1} A_{1, e x} \frac{\partial T_{1}}{\partial r_{1}}=-k_{2} A_{2, \text { in }} \frac{\partial T_{2}}{\partial r_{2}}
$$

Since these two cylinders are concentric with one another, $A_{1, \text { ex }}=A_{2, \text { in }}$. Use a backward-difference operator for the derivative for material 1 and a forward-difference operator for the derivative in material 2 , the finite-difference equation is

$$
-\epsilon_{1, e x} T_{1, M_{1}}+\epsilon_{1, \theta x} T_{1, M_{1}-1}=-\epsilon_{2, i n} T_{2,1}+\epsilon_{2, i n} T_{2,0}
$$

Using the assumptions that the points of contact are in thermal equilibrium, $T_{1, M 1}=T_{2,0}$, we have 


$$
+\epsilon_{1, \theta x} T_{1, M_{1}-1}-\left(\epsilon_{1, \theta x}+\epsilon_{2, i n}\right) T_{1, M_{1}}+\epsilon_{2, i n} T_{2,1}=0
$$

Averaging the equation at time-steps $n$ and $n+1$ for the crankNicolson method yields

$$
\begin{aligned}
& \epsilon_{1, \theta x} T_{1, M_{1}-1}^{n+1}-\left(\epsilon_{1, \theta x}+\epsilon_{2, i n}\right) T_{1, M_{1}}^{n+1}+\epsilon_{2, i n} T_{2,1}^{n+1} \\
= & -\epsilon_{1, \theta x} T_{1, M_{1}-1}^{n}+\left(\epsilon_{1, \theta x}+\epsilon_{2, i n}\right) T_{1, M_{1}}^{n}-\epsilon_{2, i n} T_{2,1}^{n}
\end{aligned}
$$

The system of equations to solve are similar to those derived for a single material except at the boundary where the two materials come in contact with one another. For the case of concentric materials, the matrices $A, B, C, T^{n}$, and $T^{n+1}$, become

$$
A=\left[\begin{array}{cccccc}
2+2 \gamma_{1} \beta_{1, \text { in }}-2 \delta_{1} \lambda_{1, \text { in }} & -2 \gamma_{1} & 0 & \ldots & 0 & 0 \\
-\gamma_{1}+\delta_{1} & 2+2 \gamma_{1} & -\gamma_{1}-\delta_{1} & \ldots & 0 & 0 \\
\cdot & \cdot & \cdot & \cdot & . & . \\
\cdot & \cdot & \epsilon_{1, \text { ex }} & -\epsilon_{1, e x}-\epsilon_{2, \text { in }} & \epsilon_{2, \text { in }} & \cdot \\
\cdot & \cdot & \cdot & \cdot & \cdot & . \\
0 & 0 & \cdots & -\gamma_{2}+\delta_{2} & 2+2 \gamma_{2} & -\gamma_{2}-\delta_{2} \\
0 & 0 & \cdots & 0 & -2 \gamma_{2} & 2+2 \gamma_{2} \beta_{2, \theta x}+2 \delta_{2} \lambda_{2, \theta x}
\end{array}\right]
$$

(19)

$$
B=\left[\begin{array}{cccccc}
2-2 \gamma_{1} \beta_{1, \text { in }}+2 \delta_{1} \lambda_{1, \text { in }} & 2 \gamma_{1} & 0 & \ldots & 0 & 0 \\
\gamma_{1}-\delta_{1} & 2-2 \gamma_{1} & \gamma_{1}+\delta_{1} & \ldots & 0 & 0 \\
\cdot & \cdot & \cdot & \cdot & \cdot & . \\
\cdot & \cdot & -\epsilon_{1, e x} & \epsilon_{1, e x}+\epsilon_{2, i n} & -\epsilon_{2, i n} & \cdot \\
\cdot & \cdot & \cdot & \cdot & \cdot & \cdot \\
0 & 0 & \cdots & \gamma_{2}-\delta_{2} & 2-2 \gamma_{2} & \gamma_{2}+\delta_{2} \\
0 & 0 & \cdots & 0 & 2 \gamma_{2} & 2-2 \gamma_{2} \beta_{2, e x}-2 \delta_{2} \lambda_{2, e x}
\end{array}\right]
$$




$$
T^{n+1}=\left[\begin{array}{c}
T_{1,0}^{n+1} \\
T_{1,1}^{n+1} \\
\cdot \\
T_{1, M_{1}-1}^{n+1} \\
T_{1, M_{1}}^{n+1} \\
T_{2,0}^{n+1} \\
\cdot \\
T_{2, N_{2}-1}^{n+1} \\
T_{2, M_{2}}^{n+1}
\end{array}\right], \quad T^{n}=\left[\begin{array}{c}
T_{1,0}^{n} \\
T_{1,1}^{n} \\
\cdot \\
T_{1, M_{1}-1}^{n} \\
T_{1, M_{1}}^{n} \\
T_{2,0}^{n} \\
\cdot \\
T_{2, M_{2}-1}^{n} \\
T_{2, M_{2}}^{n}
\end{array}\right], \quad C=\left[\begin{array}{c}
4\left(\gamma_{1}-\delta_{1}\right) \mu_{1, i n} \\
0 \\
\cdot \\
0 \\
0 \\
0 \\
\cdot \\
0 \\
4\left(\gamma_{2}+\delta_{2}\right) \mu_{2, \text { ex }}
\end{array}\right]
$$

\section{Contacting Geometries}

For two geometries touching one another, such as part of the external surface of cylinder 1 in thermal contact with the external surface of cylinder 2 , the boundary condition is

$$
-k_{1} A_{1, \theta x} \frac{\partial T_{1}}{\partial r_{1}}=+k_{2} A_{2, \theta x} \frac{\partial T_{2}}{\partial r_{2}}
$$

where it is implied that the areas represent the thermal contact areas for the materials. Since these two cylinders are not concentric, in general we have $A_{1, e x} \neq A_{2, e x}$. Use a backwarddifference operator for the derivative for material 1 and material 2, the finite-difference equation is

$$
-\epsilon_{1, \theta x} T_{1, M_{1}}+\epsilon_{1, \theta x} T_{1, M_{1}-1}=+\epsilon_{2, \theta x} T_{2, M_{2}}-\epsilon_{2, \theta x} T_{2, M_{2}-1}
$$

Using the assumptions that the points of contact are in thermal equilibrium, $\mathrm{T}_{1, \mathrm{Ml}}=\mathrm{T}_{2, \mathrm{M} 2}$, we have

$$
+\epsilon_{1, \theta x} T_{1, M_{1}-1}-\left(\epsilon_{1, \theta x}+\epsilon_{2, \theta x}\right) T_{1, M_{1}}+\epsilon_{2, \theta x} T_{2, M_{2}-1}=0
$$

Again, averaging the equation at time-steps $n$ and $n+1$ for the Crank-Nicolson method yields

$$
\begin{aligned}
& \epsilon_{1, \theta x} T_{1, M_{1}-1}^{n+1}-\left(\epsilon_{1, \theta x}+\epsilon_{2, \theta x}\right) T_{1, M_{1}}^{n+1}+\epsilon_{2, \theta x} T_{2, M_{2}-1}^{n+1} \\
= & -\epsilon_{1, \theta x} T_{1, M_{1}-1}^{n}+\left(\epsilon_{1, \theta x}+\epsilon_{2, \theta x}\right) T_{1, M_{1}}^{n}-\epsilon_{2, \theta x} T_{2, M_{2}-1}^{n}
\end{aligned}
$$


The system of equations to solve are similar to those derived for contacting geometries: the major difference is the changing of the subscripts at the boundaries of material 2. For this case, the matrices $A, B, C, T^{n}$, and $T^{n+1}$, become

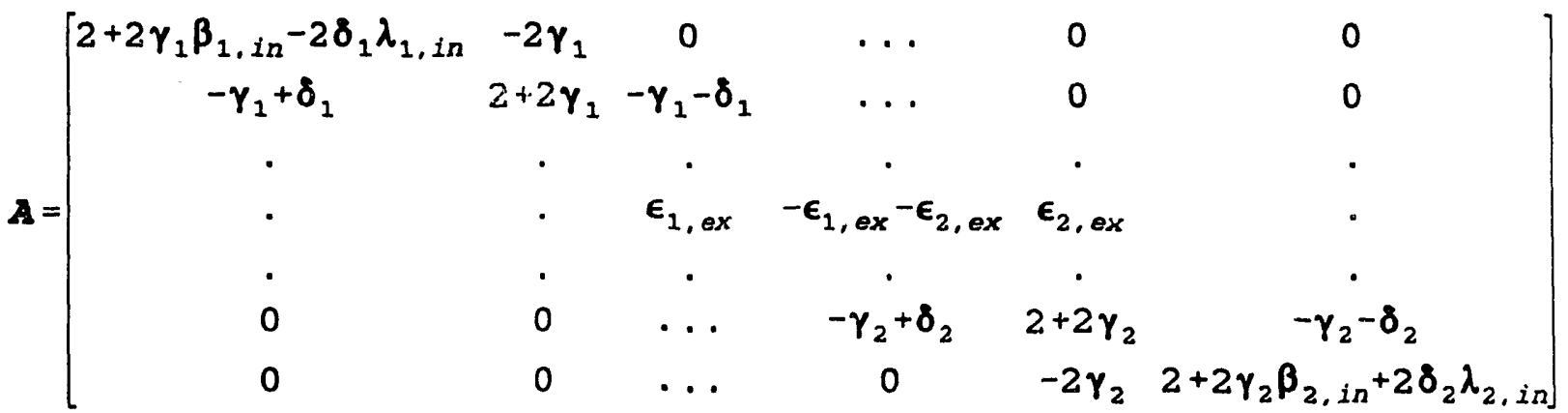

(26)

$$
B=\left[\begin{array}{cccccc}
2-2 \gamma_{1} \beta_{1, \text { in }}+2 \delta_{1} \lambda_{1, \text { in }} & 2 \gamma_{1} & 0 & \ldots & 0 & 0 \\
\gamma_{1}-\delta_{1} & 2-2 \gamma_{1} & \gamma_{1}+\delta_{1} & \ldots & 0 & 0 \\
\cdot & \cdot & \cdot & . & \cdot & . \\
\cdot & \cdot & -\epsilon_{1, e x} & \epsilon_{1, e x}+\epsilon_{2, e x} & -\epsilon_{2, e x} & \cdot \\
\cdot & \cdot & \cdot & \cdot & \cdot & . \\
0 & 0 & \cdots & \gamma_{2}-\delta_{2} & 2-2 \gamma_{2} & \gamma_{2}+\delta_{2} \\
0 & 0 & \cdots & 0 & 2 \gamma_{2} & 2-2 \gamma_{2} \beta_{2, i n}-2 \delta_{2} \lambda_{2, i n}
\end{array}\right]
$$

$$
T^{n+1}=\left[\begin{array}{c}
T_{1,0}^{n+1} \\
T_{1,1}^{n+1} \\
\cdot \\
T_{1, M_{1}-1}^{n+1} \\
T_{1, M_{1}}^{n+1} \\
T_{2, M_{2}-1}^{n+1} \\
\cdot \\
T_{2,1}^{n+1} \\
T_{2,0}^{n+1}
\end{array}\right], \quad T^{2}=\left[\begin{array}{c}
T_{1,0}^{n} \\
T_{1,1}^{n} \\
\cdot \\
T_{1, M_{1}-1}^{n} \\
T_{1, M_{1}}^{n} \\
T_{2, M_{2}-1}^{n} \\
\cdot \\
T_{2,1}^{n} \\
T_{2,0}^{n}
\end{array}\right], \quad C=\left[\begin{array}{c}
4\left(\gamma_{1}-\delta_{1}\right) \mu_{1, i n} \\
0 \\
0 \\
0 \\
0 \\
0 \\
\dot{0} \\
0 \\
4\left(\gamma_{2}+\delta_{2}\right) \mu_{2, i n}
\end{array}\right]
$$




\title{
Computer Program Testing
}

\author{
steady-state Testing
}

To the test program's ability to calculate a steady-state temperature profile for a material, the initial temperature of a material was set to $150^{\circ} \mathrm{C}$. Next, boundary conditions were applied such that the boundaries temperature values should be constant at $150^{\circ} \mathrm{C}$. The program was started and run to see how accurately the program would maintain this initial temperature.

For example, a cylinder had its internal surface temperature set to $150^{\circ} \mathrm{C}$ and had constant, convective heat loss at its external boundary to a bulk temperature of $150^{\circ} \mathrm{C}$. The program was run knowing that the temperature at all grid points should start at $150^{\circ} \mathrm{C}$ and maintain this temperature as the program marches through time steps.

The program was run with all $7 \times 7$ combinations of boundary conditions to see how accurately the program would maintain this initial temperature profile of $150^{\circ} \mathrm{C}$. Testing the program in this manner gave temperature errors of less than $0.0015^{\circ} \mathrm{C}$ and gave confidence that the algorithm would give correct steadystate temperature profiles.

\section{Transient Testing}

The program was tested on the conduction equation in rectangular coordinates for a single material with the following boundary conditions:

$$
\frac{\partial T_{i}}{\partial r_{i}}=0, \text { at } r_{i, i n}=0, \quad \frac{\partial T_{i}}{\partial r_{i}}+7 T_{i}=0, \text { at } r_{i, \theta x}=1 \mathrm{~cm}
$$

At time zero, the material was at $150^{\circ} \mathrm{C}$, and the solution compared to the analytical solution for the problem. After 20 time steps, temperature errors between the analytical and numerical solution of up to $0.04{ }^{\circ} \mathrm{C}$ were obtained, but decreased as additional time steps were taken. The accuracy of the numerical technique is considered excellent. Transient testing along with the steady-state testing satisfactorily demonstrates the ability of the program to calculate transient temperature profiles. 


\section{CONCLO8ION8}

Equations were derived and a computer program was written to solve simultaneous finite difference heat conduction equations for the transient analysis of one-dimensional heat conduction using the Crank-Nicolson algorithm. The program written is an interactive, versatile prngram which can analyze planar, cylindrical, or spherical geometries. A total of $7 \times 7$ combinations of boundary conditions can be chosen for the thermal analysis of a single material. A total of $2 \times 7 \times 7$ dj.fferent analyses can be performed on a two material systern: the materials may be concentric with one another or have their external surfaces in thermal contact with one another.

The program has been tested on its ability to calculate steadystate and transient temperatures. For the steady-state testing performed, errors in calculating steady-state temperatures were less than 0.0018 of the known value. Comparison of the result from the numerical method versus the results obtained from the analytical solution show errors well below the accuracy required for thermal fatigue analysis.

\section{REFERENCES}

1. M. Necati Özişik. Heat Conduction. p. 502. John Wiley \& Sons, Inc., New York (1980).

\section{NOTATION}

\section{subscripts}

$i=$ material index, $=1$ or 2

b = boundary index, = in for interior boundary, ex for exterior boundary

\section{symbols}

$a_{p, q}=$ element of matrix $\mathbf{A}, p=0, \ldots, M$ and $q=0, \ldots, M$

A = matrix of coefficients, defined in text 
WSK:-TR-92-501

$A_{i, b}=$ heat transfer area for material $i$ at the boundary, $m^{2}$

$b_{p, q}=$ element of matrix $B, p=0, \ldots, M$ and $q=0, \ldots, M$

B = matrix of coefficients, defined in text

$c_{p} \quad=$ element of vector $c, p=0, \ldots, M$

c = vector, defined in text

$c_{p i}=$ heat capacity for material $i, c a l / g-{ }^{\circ} \mathrm{C}$

D $=$ vector, $=$ BT $^{\mathbf{n}}+\mathbf{C}$

$f_{i, b}=$ thermal flux for material $i$ at boundary $b$, watts $/ m^{2}$

$h_{i, b}=$ heat transfer coefficient for material $i$ at boundary $b$, watts $/ \mathrm{m}^{2}-{ }^{\circ} \mathrm{C}$

$j=$ spacial parameter index, $0, \ldots, M_{i}$

$k_{i}=$ thermal conductivity for material $i$, watts $/ m-{ }^{\circ} \mathrm{C}$

$\mathrm{M}_{\mathrm{i}}=$ number of spacial grid points for material $i$

$\mathrm{n}=$ time step index, $0, \ldots, \mathrm{N}$

$\mathrm{N}=$ number of time steps

$r_{i}=$ spacial distance for material $i, \mathrm{~cm}$

$r_{i, b}=$ radius of material $i$ at boundary $b$ (I.R. and O.R. for the material), cm

$t=$ time, seconds

$T_{i, j}{ }^{n}=$ temperature of material $i$, at spacial node $j$, at time step $\mathbf{n}$

$\mathrm{T}_{\infty, b}=$ bulk media convective heat transfer temperature at boundary $b,{ }^{\circ} \mathrm{C}$

\section{Greek}

$\alpha_{i}=$ thermal diffusivity for material $i_{,}=k_{i} / \rho_{i}-C_{p i}, \mathrm{~cm}^{2} / \mathrm{sec}$

$\beta_{i, b}=1+\lambda_{i, b}$

$\gamma_{i}=$ dimensionless time for material $i,=\alpha_{i} \Delta t /\left(\Delta r_{i}\right)^{2}$ 
WSRC-TR-92-501

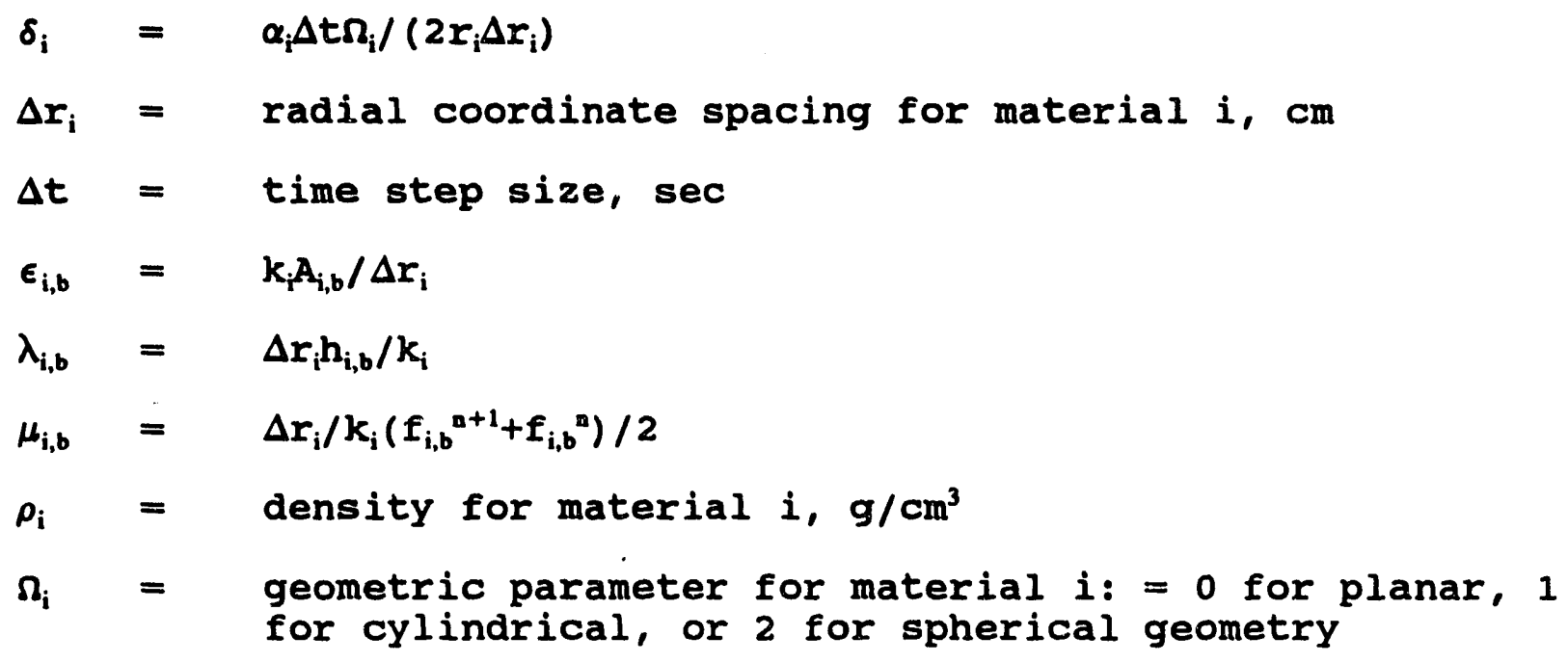


APPENDIX A. COMPUTER PROGRAY LIETING

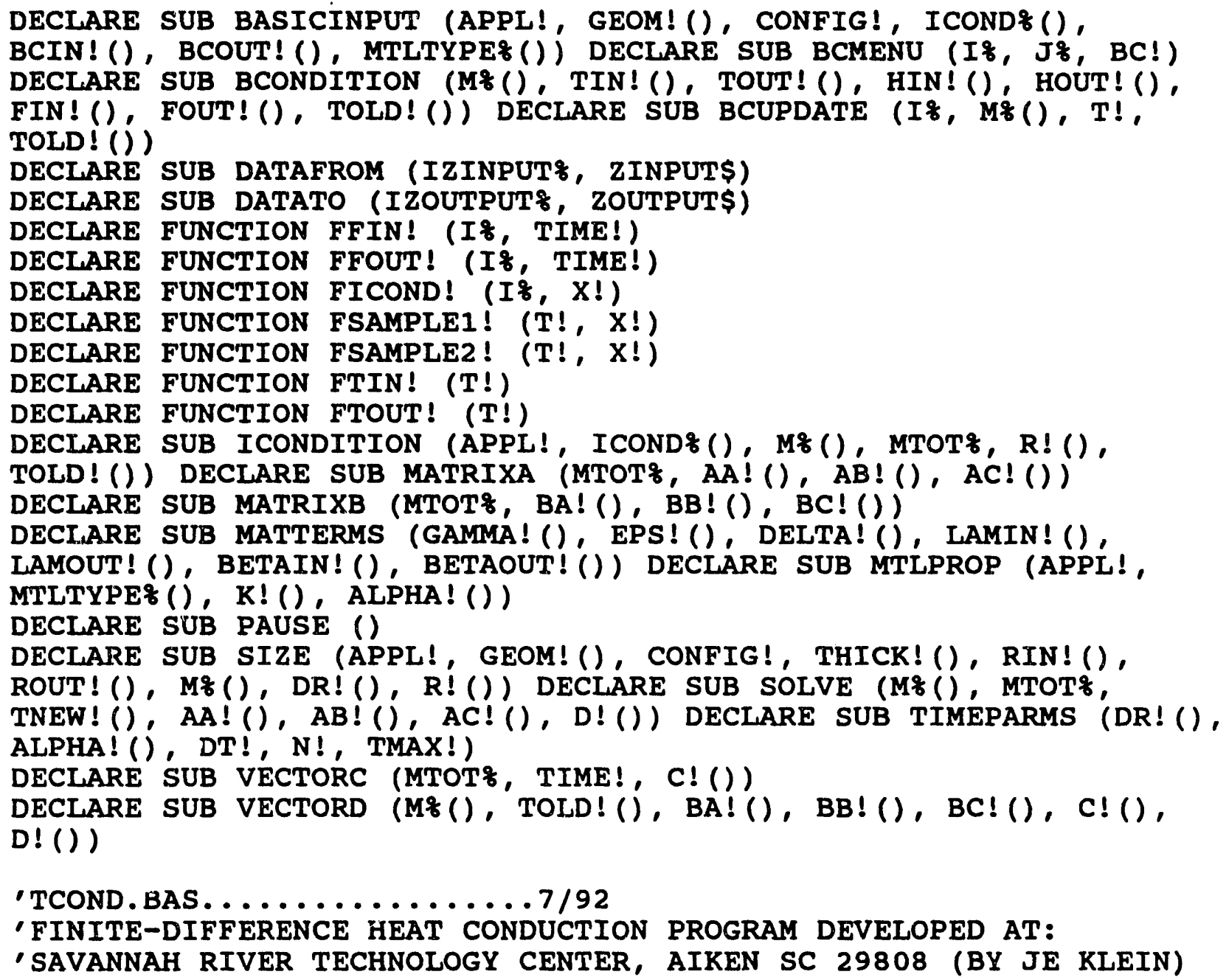

DEFIN'T I, M

$\begin{array}{ll}M 1=20 & \text { 'NUMBER OF SPACIAL GRID POINTS FOR MATERIAL } 1 \\ M 2=5 & \text { 'NUMBER OF SPACIAL GRID POINTS FOR MATERIAL } 2\end{array}$

DEBUG $=0$

$\operatorname{MMAX}=\mathrm{M} 1+\mathrm{M} 2$

DIM M(2)

DIM GEOM(2), ICOND(2), BCIN(2), BCOUT(2), MTLTYPE(2)

DIM RIN (2), ROUT(2), THICK(2), DR(2), R(2, MMAX)

DIM TOLD (MMAX), TNEW (MMAX), TZERO (2)

DIM TIN(2), TOUT(2), HIN(2), HOUT(2), FIN(2), FOUT(2) 
DIM K(2), ALPHA (2), GAMMA (2), DELTA(MMAX)， LAMIN (2), LAMOUT(2)

DIM BETAIN(2), BETAOUT(2), AREA(2), EPS(2)

DIM LA (MMAX), AB (MMAX), AC (MMAX)

DIM BA (MMAX), BB (MMAX), BC (MMAX)

DIM C(MMAX), D(MMAX)

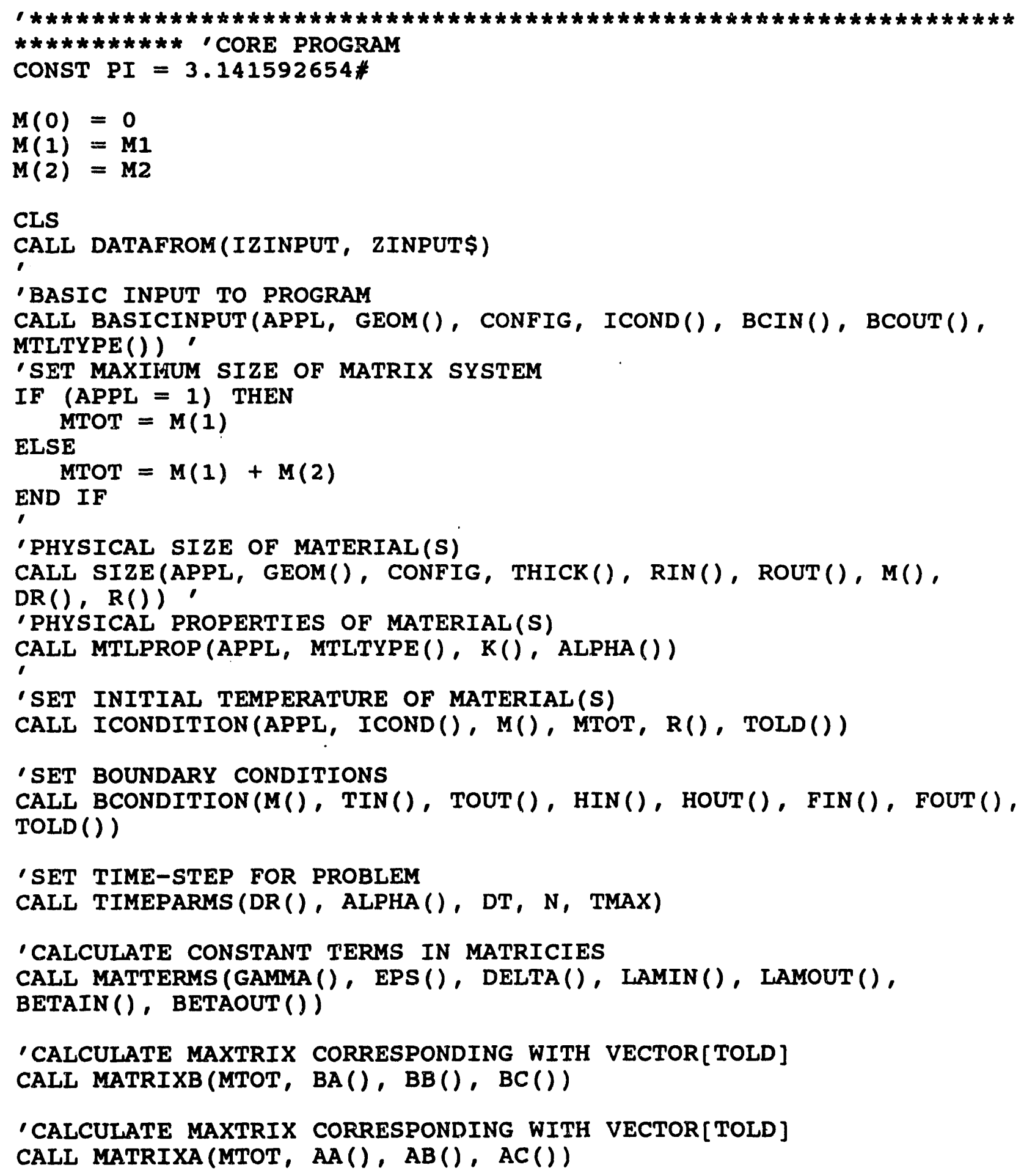


CALL DATATO (IZOUTPUT, ZOUTPUT\$)

'CALCULATE NUMBER OF TIME STEPS

$N=\operatorname{INT}(N)+1$

IF $N<20$ THEN $N=20$

DELTAMAX $=0$ !

IF $(M(1)>10)$ THEN PSTEP1 $=\operatorname{INT}(M(1) / 10)$

FOR TSTEP $=1$ TO $\mathrm{N}-1$

TIME $=$ TSTEP $* D T$

IF (TSTEP $>0)$ THEN TIMEOLD $=($ TSTEP -1$) * D T$

CALL VECTORC(MTOT, TIME, C())

' UPDATE B.C. IF TEMP. IS FUNCTION OF TIME $I=1$ IF $(B C I N(I)=5)$ THEN

' FOR MATERIAL 1 INSIDE B.C. END IF $I=A P P L$

IF $(B C O U T(I)=5)$ THEN

CALL BCUPDATE(I, M(), TIMEOLD, TOLD( ))
END IF

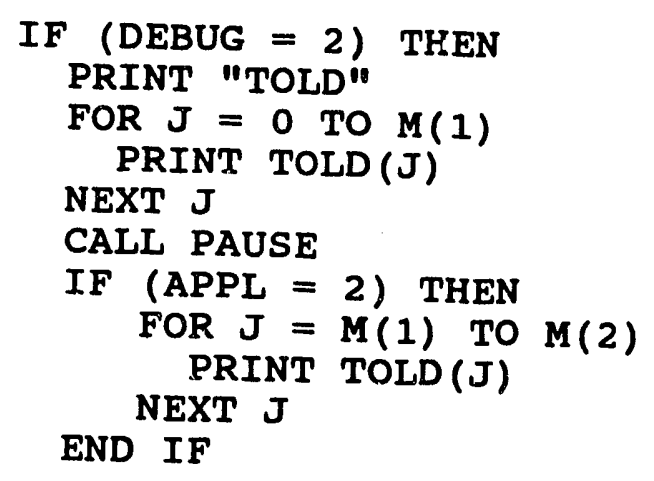

END IF

'CALCULATE VECTOR D: VECTOR[D] = MATRIX[B] * VECTOR[TOLD] + VECTOR $[C] \quad$ CALL VECTORD(M(), TOLD ()$, B A(), B B(), B C(), C()$,
$D())$

' CALCULATE TEMPERATURES AT NEW TIME: SOLVE FOR VECTOR[TNEW] MATRIX [A] * VECTOR(TNEW) = VECTOR[D] = MATRIX[B] * VECTOR[TOLD] + VECTOR[C] CALL SOLVE(M(), MTOT, TNEW(), AA(),AB(),AC(), D( ))

CLS

DELTAT = TNEW $(M(1))-\operatorname{TNEW}(0)$

IF (ABS (DELTAT) > ABS (DELTAMAX)) THEN

DELTAMAX = DELTAT

TIMEDTMAX $=$ TIME 
END IF

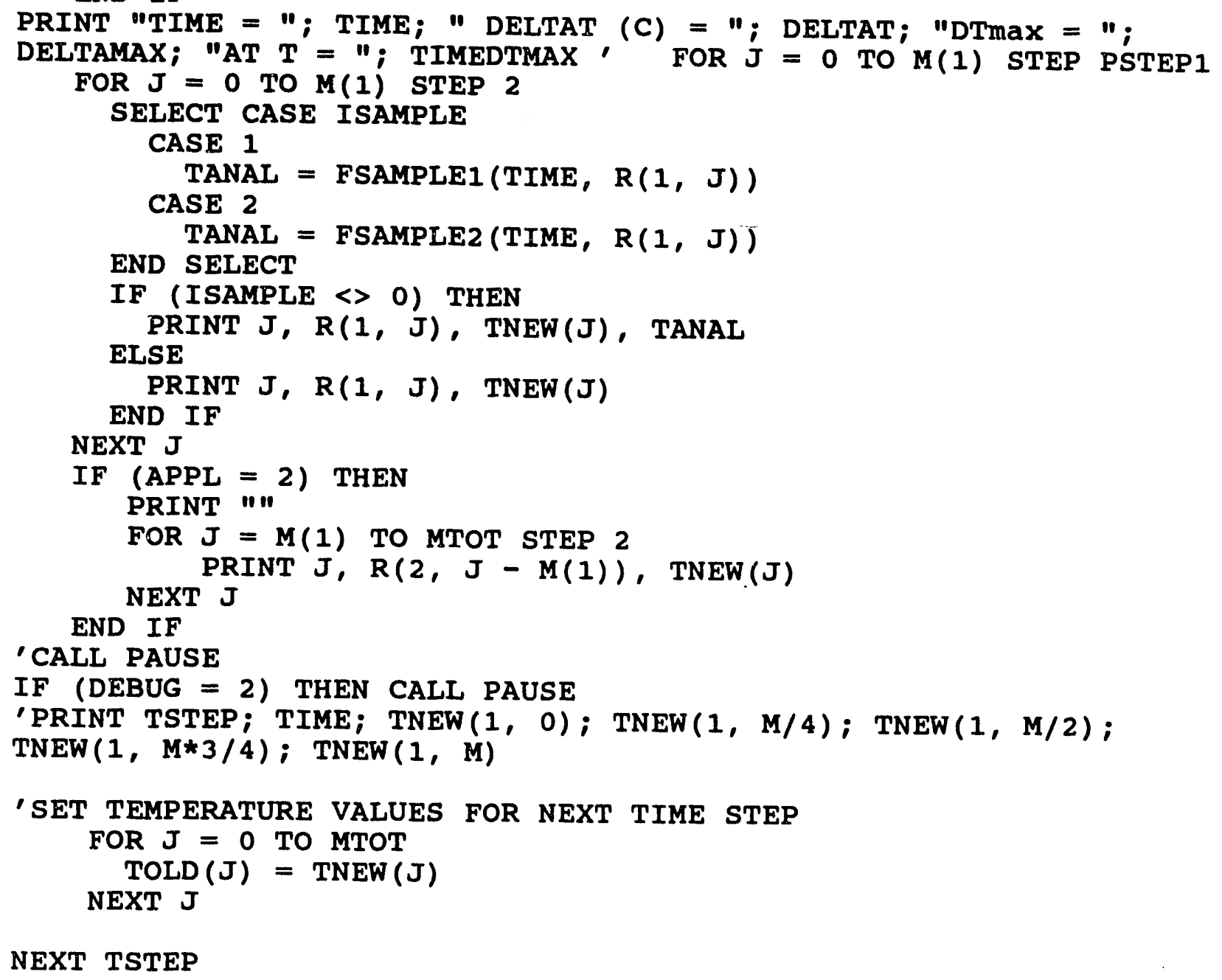


WSRC-TR-92-501

CASE 1

PRINT SPC(7); "CYlinder"

PRINT SPC (10); "Inner radius (in.)="; $R I N(1)$, "Outer radius (in.) $="$; ROUT (1) CASE 2

PRINT SPC (7); "Sphere"

PRINT SPC(10); "Inner radius (in.)="; RIN(1), "Outer radius (in.) $=" ;$ ROUT (1) END SELECT

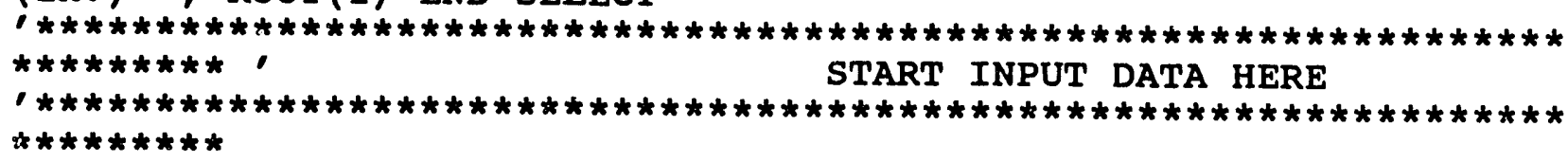

DEFINT J

SUB BASICINPUT (APPL, GEOM(), CONFIG, ICOND(), BCIN(), BCOUT(), MTLTYPE()) SHARED ZINPUT\$, DENT\$, ISAMPLE

' FUNDEMENTAL INPUT FOR PROGRAM

CLS

SELECT CASE ZINPUT\$

CASE IS = "KYBD:"

ISAMPE $=0$

INPUT "COMPARE TO ANALYTICAL SOLUTION? $(\mathrm{Y} / \mathrm{N}):$ ", A\$

IF ( $A \$=$ "Y" OR A\$ = "Y") THEN

END IF

INPUT "ENTER SAMPLE PROBLEM NUMBER ", ISAMPLE

CLS

PRINT "PROGRAM TCOND.BAS FOR DIFFUSION CALCULATIONS "; DATE\$; CHR\$(13) SELECT CASE ISAMPLE

CASE 0

INPUT "Identification name and/or number for analysis"; DENT\$:

PRINT " " PRINT " APPLICATION DESIRED"

PRINT "1. Single Material Conduction (Default)"

PRINT "2. Coupled Material Conduction"

'PRINT "3. ": PRINT ""

INPUT "OPTION"; APPL: PRINT " "

IF $($ APPL $=0)$ THEN APPL $=1$

CASE 1

$\mathrm{APPL}=1$

CASE 2

APPL $=1$

END SELECT

CONFIG $=0$

IF (APPL $=2$ ) THEN

PRINT

PRINT "1. Concentric Layers (Default)"

PRINT "2. Contacting Geometrys "

'PRINT "3. ": PRINT " "

INPUT "OPTION"; CONFIG: PRINT "" 


\section{END IF}

IF (CONFIG $=0)$ THEN CONFIG $=1$

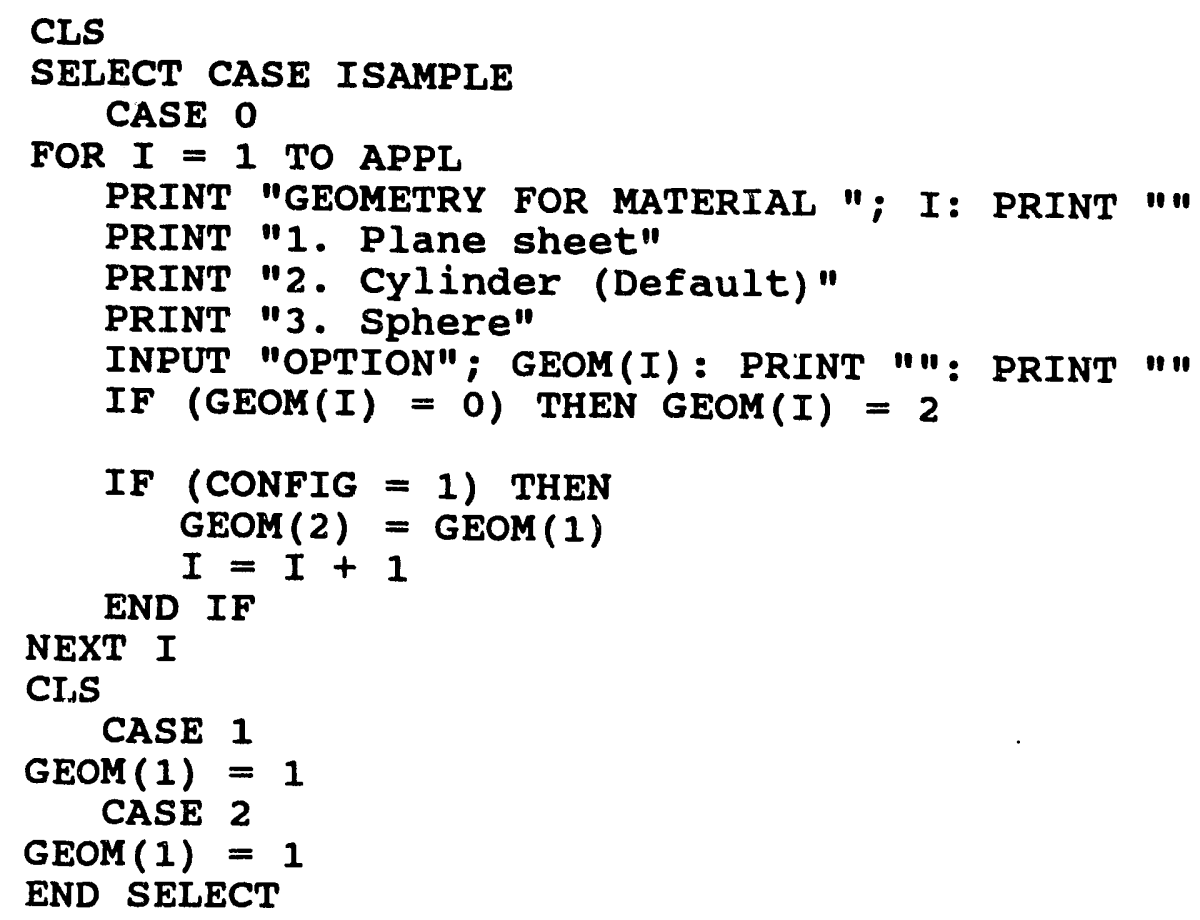

'SET PARAMETERS DESCRIBING INITIAL CONDITIONS SELECT CASE ISAMPLE

CASE 0

FOR $I=1$ TO APPL

PRINT "INITIAL CONDITION FOR MATERIAL "; I: PRINT ""

PRINT " 1 . Constant Temperature Profile (Default)"

PRINT "2. Variable Temperature Profile (User Entered)"

PRINT "3. Variable Temperature Profile (Function Generated)" INPUT "OPTION"; ICOND(I): PRINT "": PRINT " "

NEXT I

IF $(I \operatorname{COND}(I)=0)$ THEN $\operatorname{ICOND}(I)=1$

CLS

CASE 1

$\operatorname{ICOND}(1)=3$

CASE 2

$\operatorname{ICOND}(1)=1$

END SELECT

' SET PARAMETERS DESCRIBING BOUNDARY CONDITIONS SELECT CASE ISAMPLE CASE 0

FOR I $=1$ TO APPL

IF (CONFIG $=0$ ) THEN

CALL BCMENU (1, 1, BCIN (1)) 


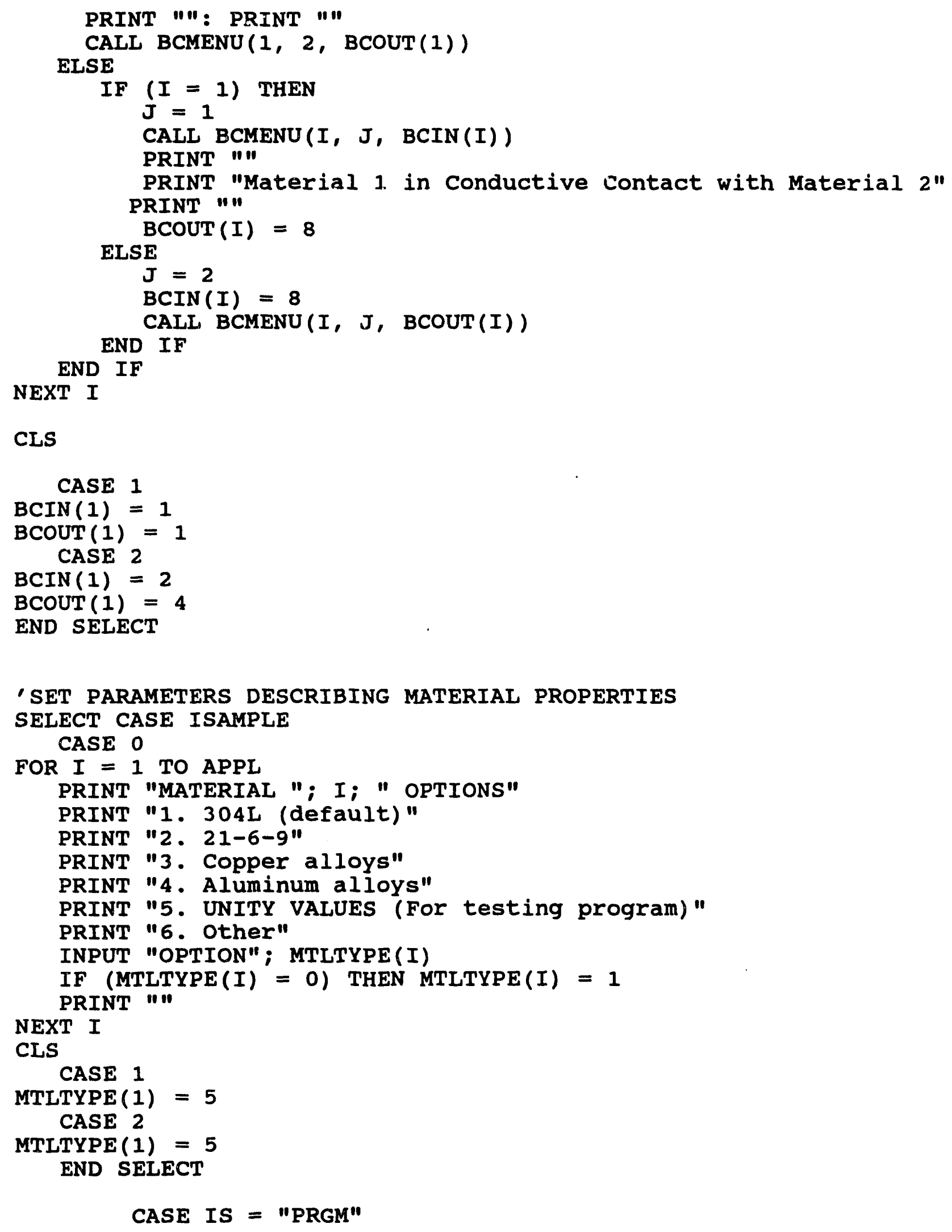


READ DENT\$

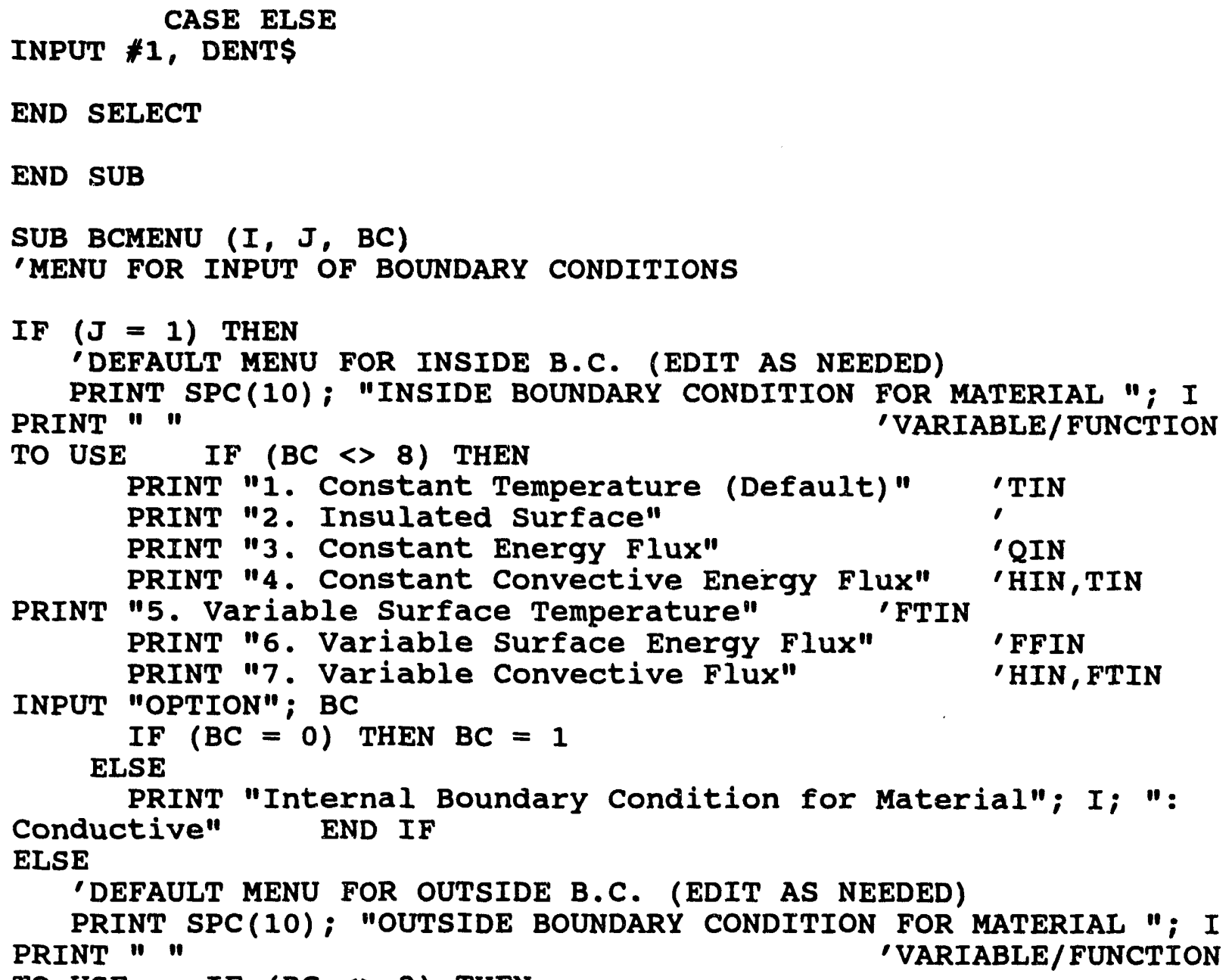
TO USE IF (BC $\gg$ 8) THEN

PRINT "1. Constant Temperature (Default)" "TOUT

PRINT "2. Insulated Surface"

PRINT "3. Constant Energy Flux" "QOUT

PRINT "4. Constant Convective Energy Flux" 'HOUT, TOUT

PRINT "5. Variable Surface Temperature" 'FTOUT

PRINT "6. Variable Surface Energy Flux" 'FFOUT

PRINT "7. Variable Convective Flux" 'HOUT, FTOUT INPUT "OPTION"; BC

IF $(B C=0)$ THEN $B C=1$

ELSE

PRINT "External Boundary Condition for Material"; I; ": Conductive"

END IF

END SUB

SUB BCONDITION (M(), TIN(), TOUT(), HIN (), HOUT(), FIN(), FOUT(), TOLD( ) ) SHARED APPL, BCIN(), BCOUT(), ISAMPLE, CONFIG, AREA() 


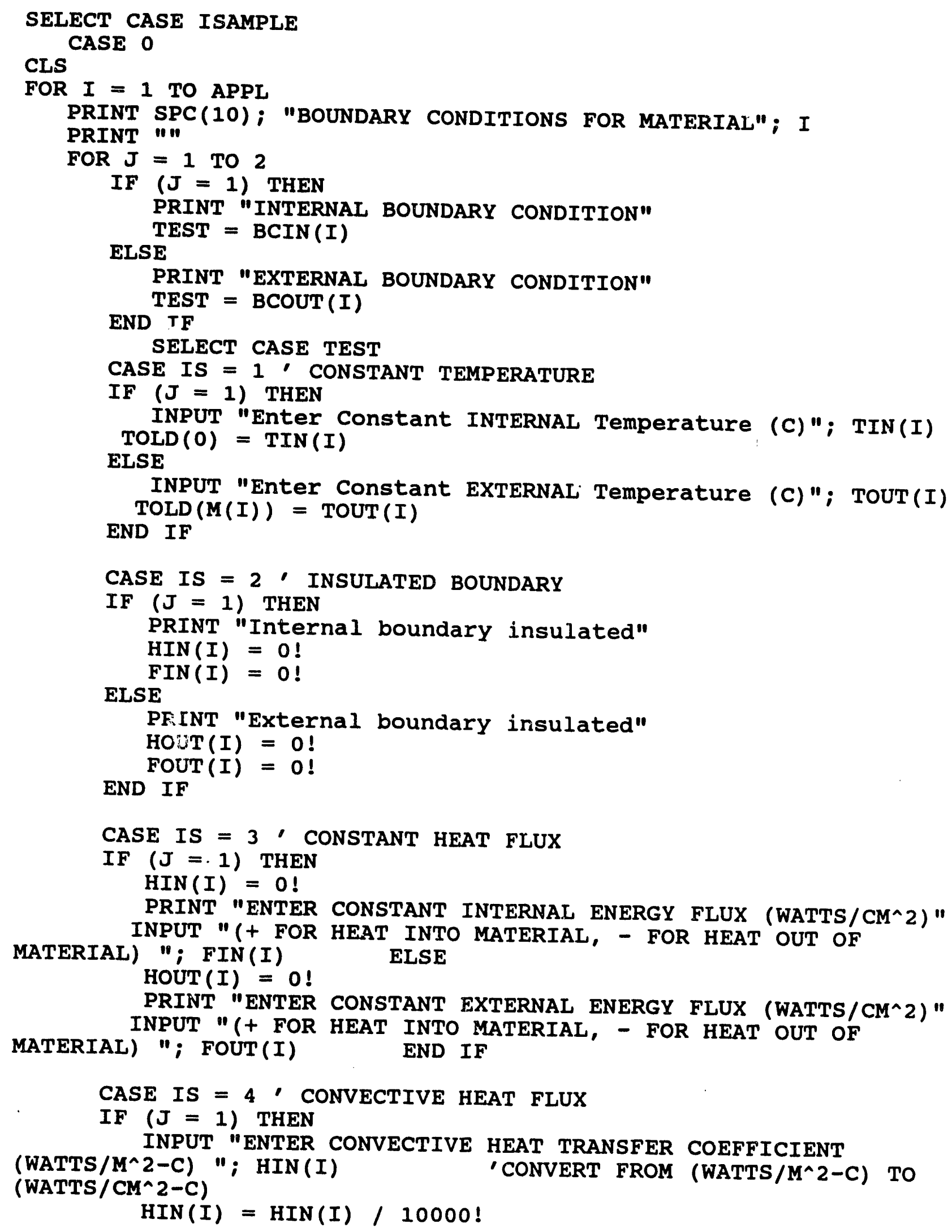


(C) "; $\operatorname{TIN}(I)$

INPUT "ENTER CONSTANT CONVECTIVE 'BULK' TEMPERATURE

ELSE

$\operatorname{FIN}(I)=\operatorname{HIN}(I) * \operatorname{TIN}(I)$

' (WATTS/CM^2)

INPUT "ENTER CONVECTIVE HEAT TRANSFER COEFFICIENT (WATTS $/ M^{\wedge} 2-C$ ) "; HOUT(I)
(WATTS/CM^2-C) HOUT $(I)=$ HOUT $(I) / 10000 !$

(C) " ; $\operatorname{TOUT}(\mathrm{I})$

INPUT "ENTER CONSTANT CONVECTIVE 'BULK' TEMPERATURE

(WATTS/CM^2)

'FOUT $(I)=\operatorname{HOUT}(I) * \operatorname{TOUT}(I)$

END IF

CASE IS $=5$

IF $(J=1)$ THEN

PRINT "Internal surface temperature as a function of

time must be"

VERIFY BEFORE CONTINUING"

ELSE TOLD $(0)=$ FTIN $(0 !)$

CALL PAUSE

time must be"

PRINT "External surface temperature as a function of

VERIFY BEFORE CONTINUING"

END IF $\operatorname{TOLD}(M(I))=$ FTOUT $(0 !)$

CALL PAUSE

CASE IS $=6$

IF $(J=1)$ THEN

time must be"

PRINT "Internal surface ENERGY flux as a function of

VERIFY BEFORE CONTINUING"

PRINT "entered into subroutine FFIN.

ELSE

CALL PAUSE

PRINT "External surface ENERGY flux as a function of

time must be"

VERIFY BEFORE CONTINUING"

PRINT "entered into subroutine FFOUT.

END IF

CALL PAUSE

CASE IS $=7$

IF $(J=1)$ THEN

INPUT "ENTER CONVECTIVE HEAT TRANSFER COEFFICIENT

(WATTS/M^2-C) "; HIN (I)

(WATTS/CM^2-C)

' CONVERT FROM (WATTS/M^2-C) TO

$\operatorname{HIN}(I)=\operatorname{HIN}(I) / 10000$ !

time must be"

VERIFY BEFORE CONTINUING"

ELSE

INPUT "ENTER CONVECTIVE HEAT TRANSFER COEFFICIENT

(WATTS/M^2-C) "; $\operatorname{HOUT}(\mathrm{I})$

(WATTS/CM^2-C)

' CONVERT FROM (WATTS/M^2-C) TO

HOUT $(I)=$ HOUT $(I) ~ / 10000$ !

time must be"

PRINT "Internal surface temperature as a function of

PRINT "entered into subroutine FTOUT. 
VERIFY BEFORE CONTINUING" END IF

CALL PAUSE

CASE IS $=8$

PRINT "Coupled Problem Chosen - B.C. fixed"

IF $(I=1)$ THEN

$\operatorname{AREA}(1)=1$ !

IF (CONFIG $=2$ ) THEN

INPUT "Enter EXTERNAL conductive area for material

$1(\mathrm{CM} 2 / \mathrm{CM})$ "; AREA (1)

ELSE

END IF

AREA (2) $=1$ !

IF (CONFIG $=2$ ) THEN

INPUT "Enter EXTERNAL conductive area for material

$2\left(C^{\wedge} 2 / C M\right) " ; \operatorname{AREA}(2)$

END IF

PRINT ""

END SELECT

NEXT $J$

PRINT " "

NEXT I

CASE 1

$$
\begin{aligned}
& \operatorname{TOLD}(0)=0 ! \\
& \operatorname{TOLD}(M(1))=0 !
\end{aligned}
$$

CASE 2

$$
\begin{aligned}
& \operatorname{HIN}(I)=0 ! \\
& \operatorname{FIN}(I)=0 ! \\
& \operatorname{HOUT}(1)=70000 ! \\
& \operatorname{HOUT}(1)=\operatorname{HOUT}(1) / 10000 ! \\
& \operatorname{TOUT}(1)=0 \\
& \text { FOUT }(1)=\operatorname{HOUT}(1) \star \operatorname{TOUT}(1) \quad(\text { WATTS/CM^2) }
\end{aligned}
$$

END SELECT

END SUB

DEFSNG $J$

SUB BCUPDATE (I, M(), TIME, TEMP())

SHARED BCIN(), BCOUT()

' UPDATE B.C. TEMP. WHEN TEMP. IS A FUNCTION OF TIME

IF $(B C I N(1)=5)$ THEN
TEMP $(0)=$ FTIN (TIME)
END IF

IF $(B \operatorname{COUT}(I)=5)$ THEN

IF $(I=1)$ THEN

ELSE

$\operatorname{TEMP}(M(I))=$ FTOUT $(T I M E)$

$\operatorname{TEMP}(M(I))=$ FTOUT $(T I M E)$ 


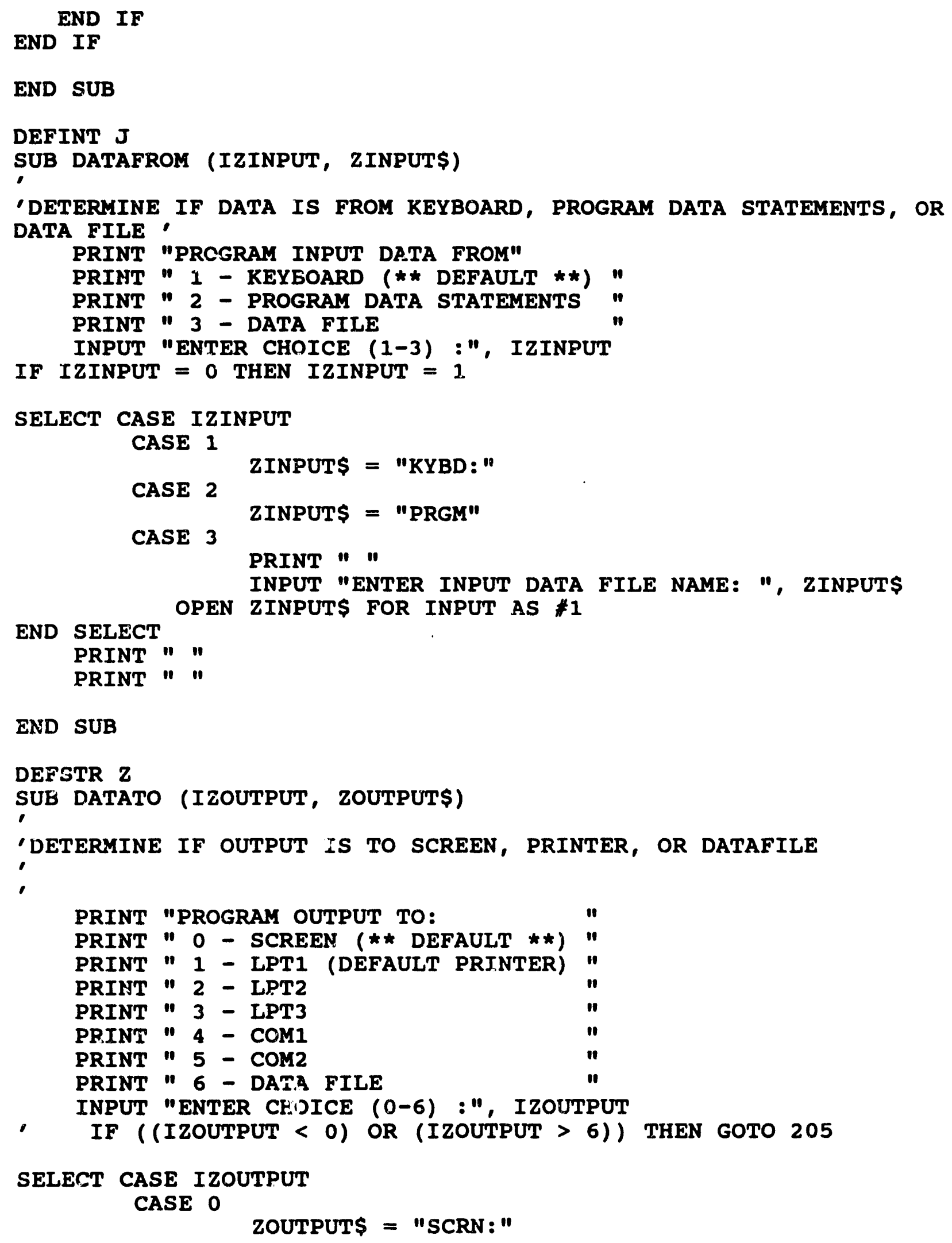


CASE 1

CASE 2 ZOUTPUTS = "LPT1:"

ZOUTPUTS = "LPT2:"

CASE 3 ZOUTPUT\$ = "LPT3:"

CASE 4

zOUTPUT\$ = "COM1:"

CAsE 5

CASE 6

ZOUTPUT\$ = "COM2:"

END SELECT

PRINT " "

INPUT "ENTER OUTPUT DATA FILE NAME: ", ZOUTPUT\$

OPEN ZOUTPUTS FOR OUTPUT AS \#2

PRINT " "

PRINT " "

END SUB

DEFINT K-L, N

DEFSNG $\mathrm{Z}$

SUB DESCRIPT

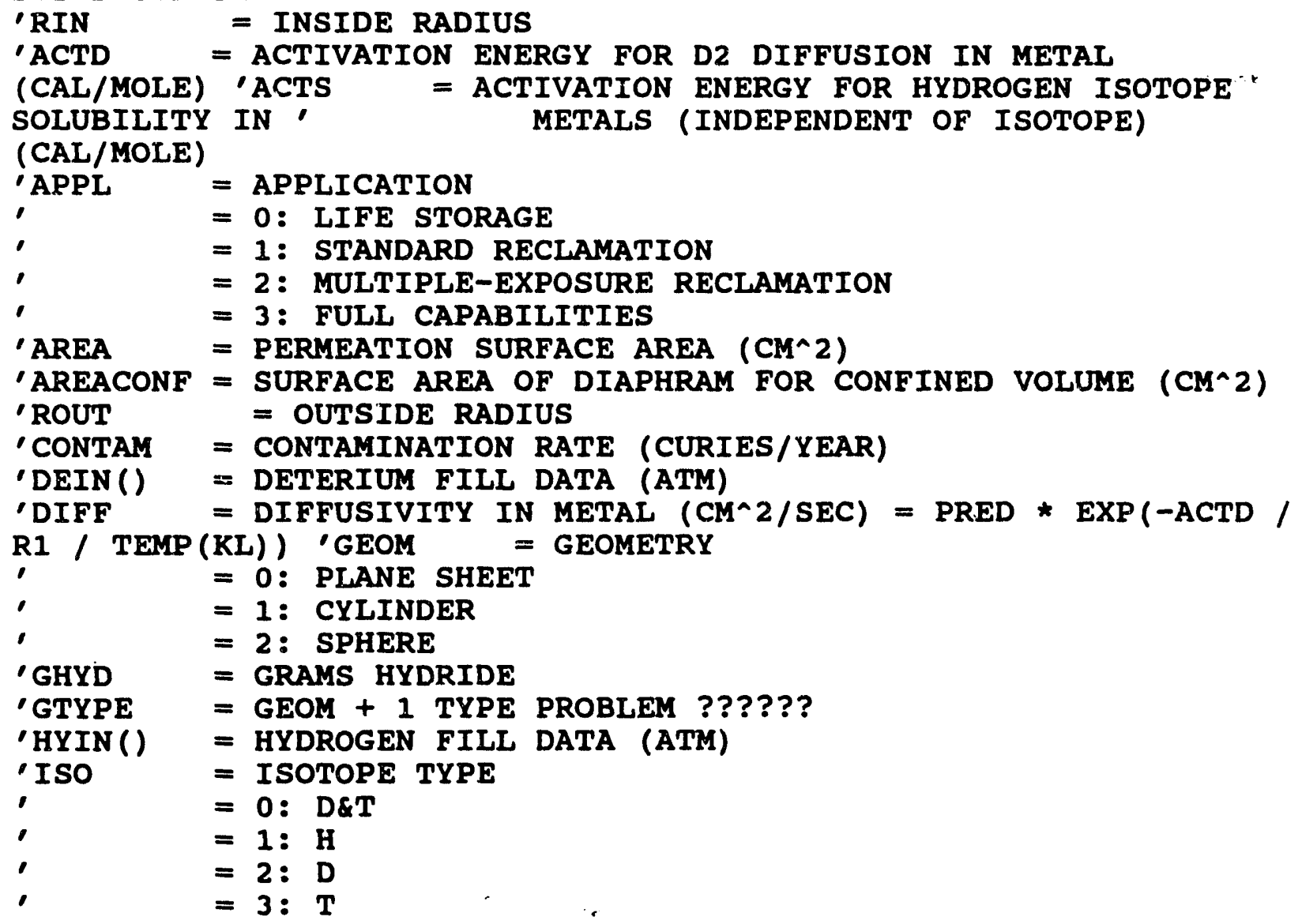




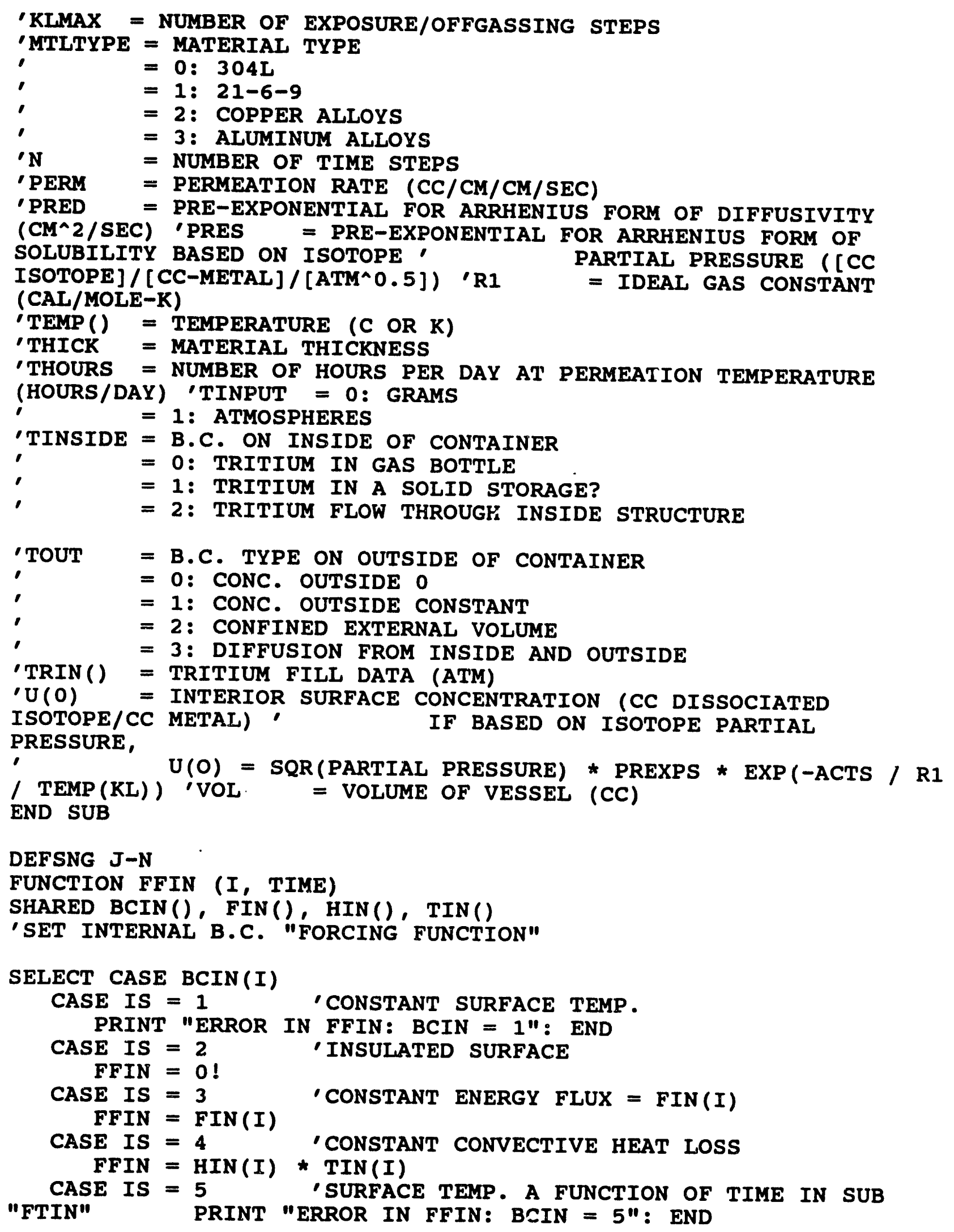


WSRC-TR-92-501

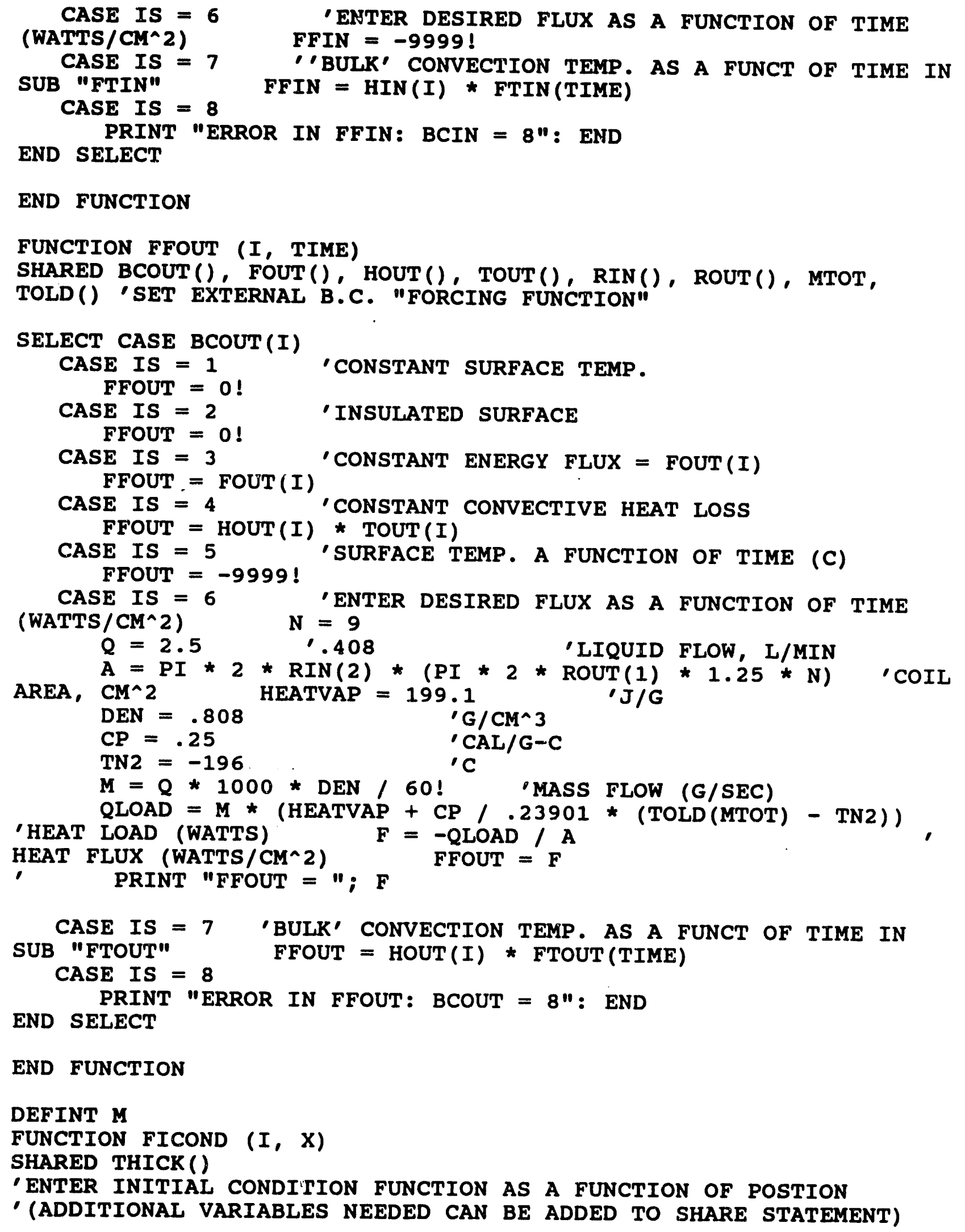




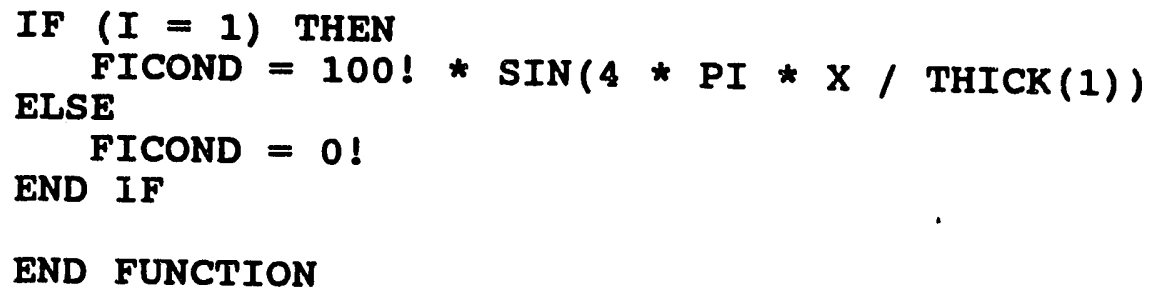

FUNCTION FSAMPLE1 ( $T, X)$

SHARED THICK(), ALPHÁ() FSAMPLE1 $=100 ! * \operatorname{EXP}(-16 ! * \mathrm{PI} \wedge 2 * \operatorname{ALPHA}(1) * \mathrm{~T} / \operatorname{THICK}(1)$ औ
2) SIN $(4 ! * \mathrm{PI} * \mathrm{X} / \operatorname{THICK}(1))$

END FUNCTION

FUNCTION FSAMPLE2 ( $T, X)$

SHARED APPL, PLPHA (), HOUT(), THICK(), TZERO()
DIM B (6)

'ANALYTICAL SOLUTION FOR PROBLEM IN RECTANGULAR COORDINATES , $\mathrm{DT} / \mathrm{DX}=0 \mathrm{AT} X=0, \mathrm{DT} / \mathrm{DX}+\mathrm{H} 2 \mathrm{~T}=0 \mathrm{AT} X=\mathrm{L}, \mathrm{T}=\mathrm{TO}$ AT $\mathrm{T}=0$

( $\mathrm{K}$ IS ASSUMED TO BE 1 , THICK $=0.3937$ IN $=1 \mathrm{CM}$ )

'FIRST SIX ROOTS ARE FÓR SOLUTION WHEN $L=.3937$ IN (1CM) AND , $\mathrm{H} 2=7 \mathrm{E}+4$ WATTS $/ \mathrm{M} \wedge 2-\mathrm{C}$

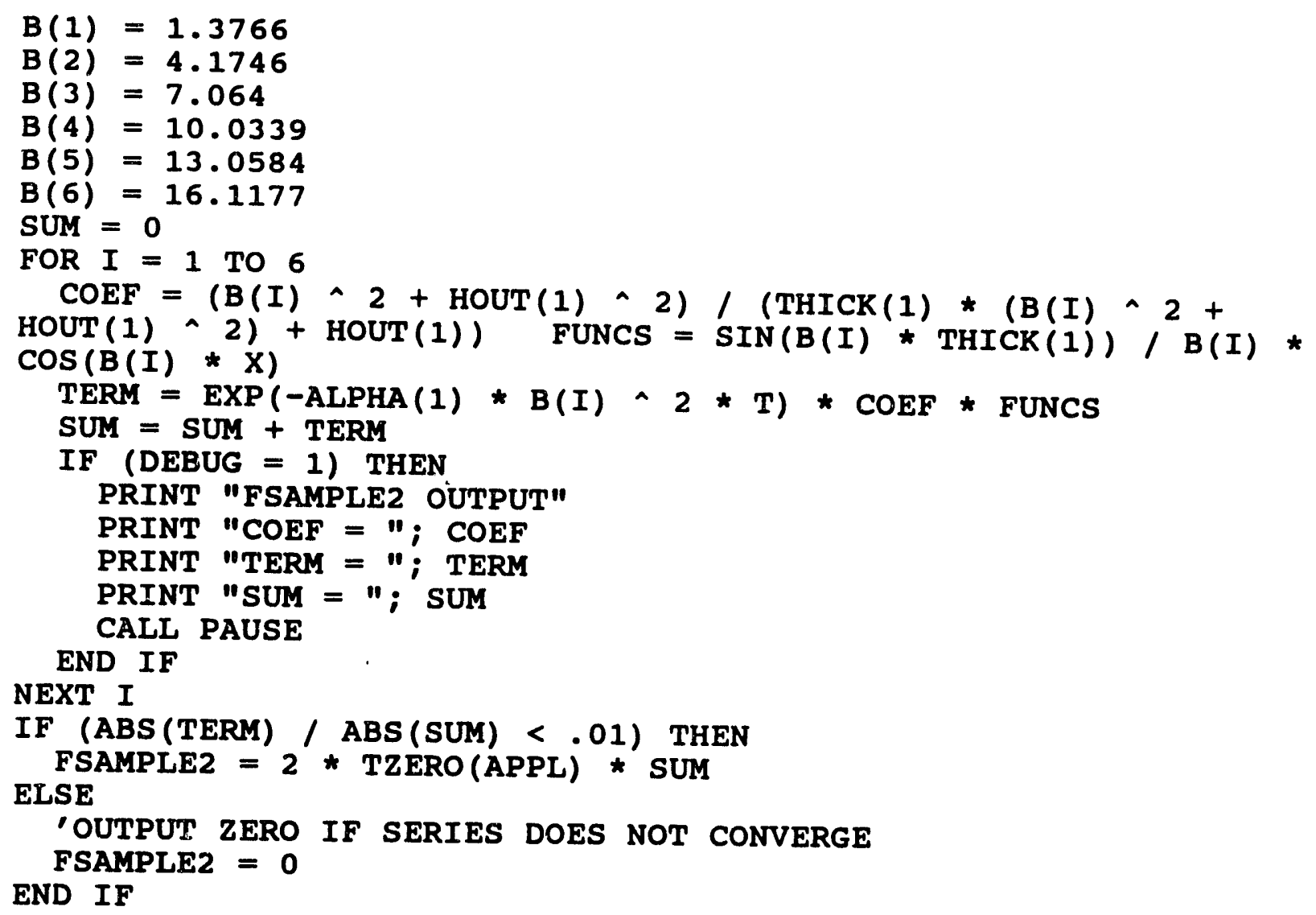


END FUNCTION

FUNCTION FTIN (TIME)

SHARED HIN (), TZERO (), TOLD(), RIN()

' ENTER INTERNAL BOUNDARY CONDITION AS A FUNCTION OF TIME

'ADD VARIABLES NEED TO SHARE STATEMENT

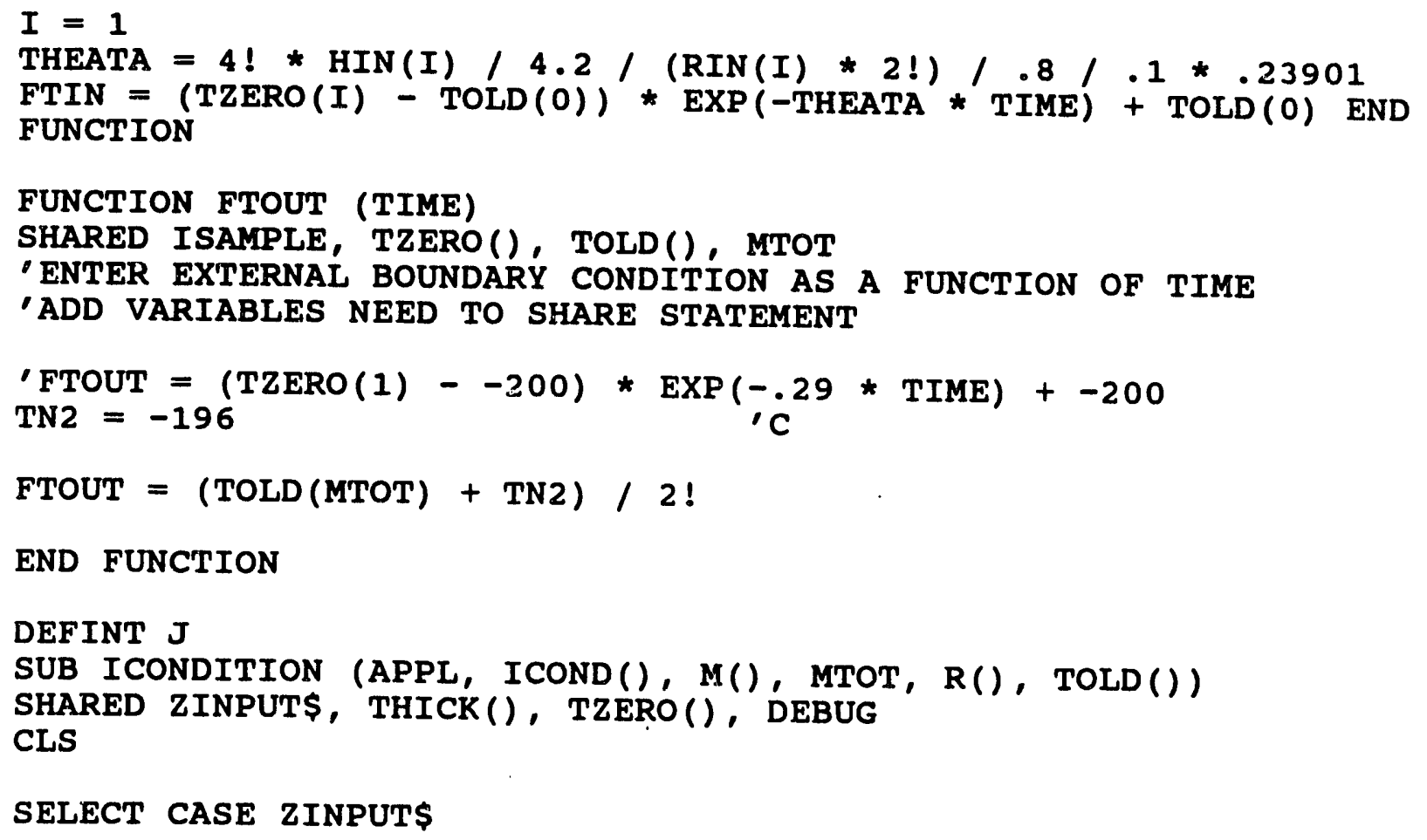


ELSE

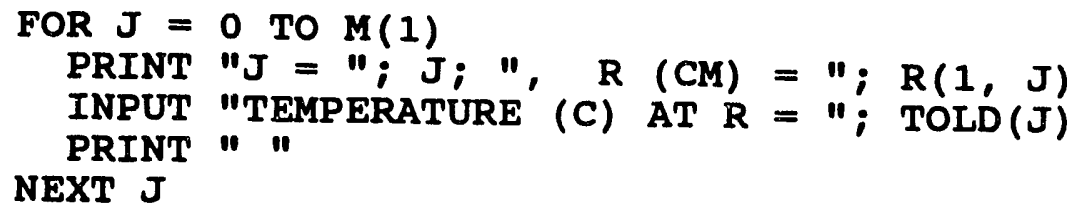

END SELECT

PRINT " ": PRINT ""

NEXT I

CLS

READ DENT\$

CASE IS = "PRGM"

\section{CASE ELSE \\ INPUT \#1, DENT\$}

END SELECT

IF (DEBUG $=1$ ) THEN

FOR $I=1$ TO APPL

PRINT "INITIAL CONDITIONS"

$$
\text { FOR } J=M(I-1) \text { TO } M(I-1)+M(I)
$$

TOLD $=" ; \operatorname{TOLD}(J)=" J=J_{i} ", \frac{R}{N E X T}$ PRINT "J = "i J " $R(C M)=" i$ CALL PAUSE

NEXT I CLS

END IF

END SUB 
SUB MATRIXA (MTOT, AA(), $A B(), A C())$

SHARED APPL, $M(), B C I N(), B C O U T(), D E B U G, E P S()$

SHARED GAMMA (), DELTA (), LAMIN (), LAMOUT( ), BETAIN(), BETAOUT( )

'SET-UP MATRIX OF COEFFICIENTS FOR KNOWN TEMPERATURES

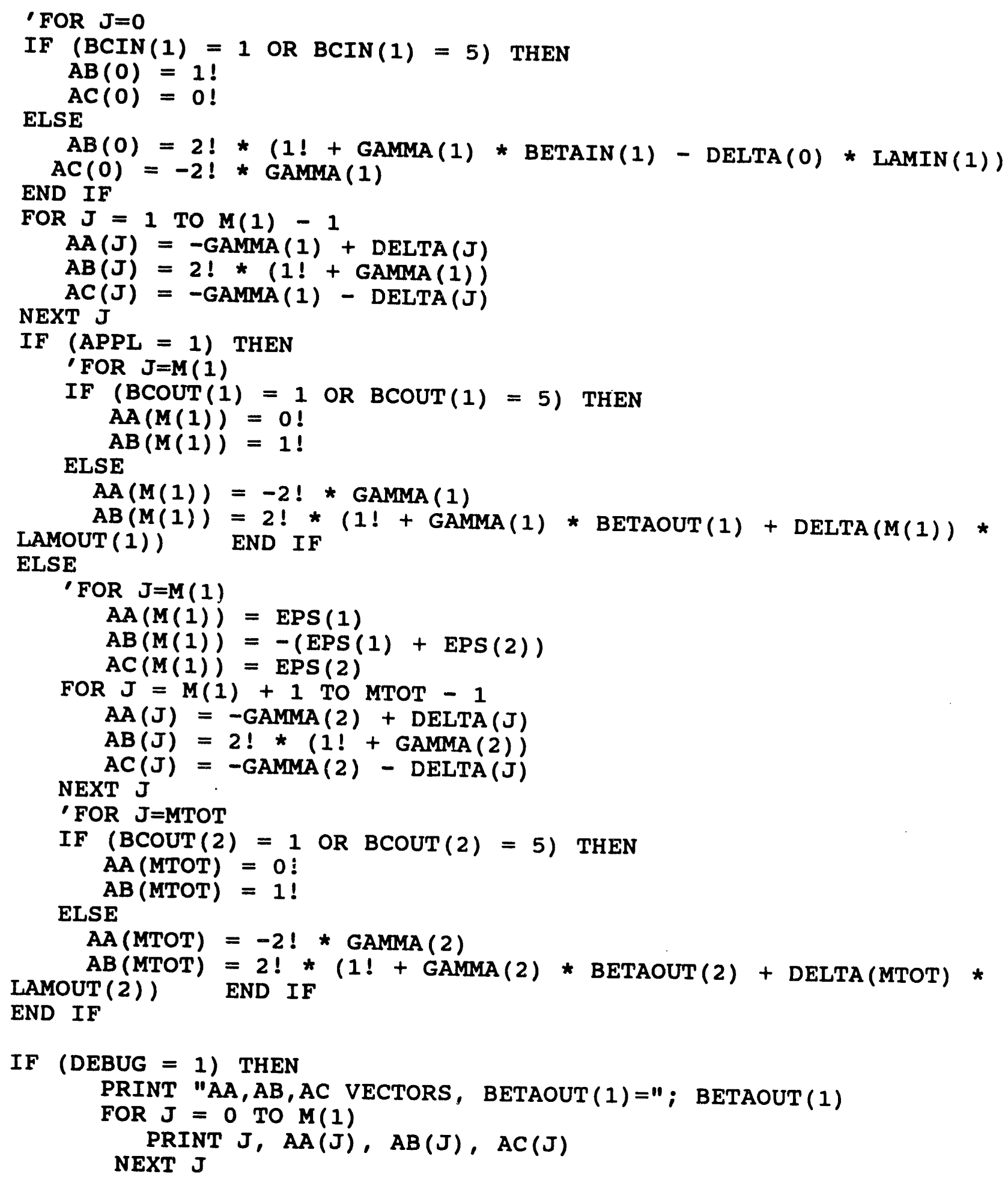


WSRC-TR-92-501

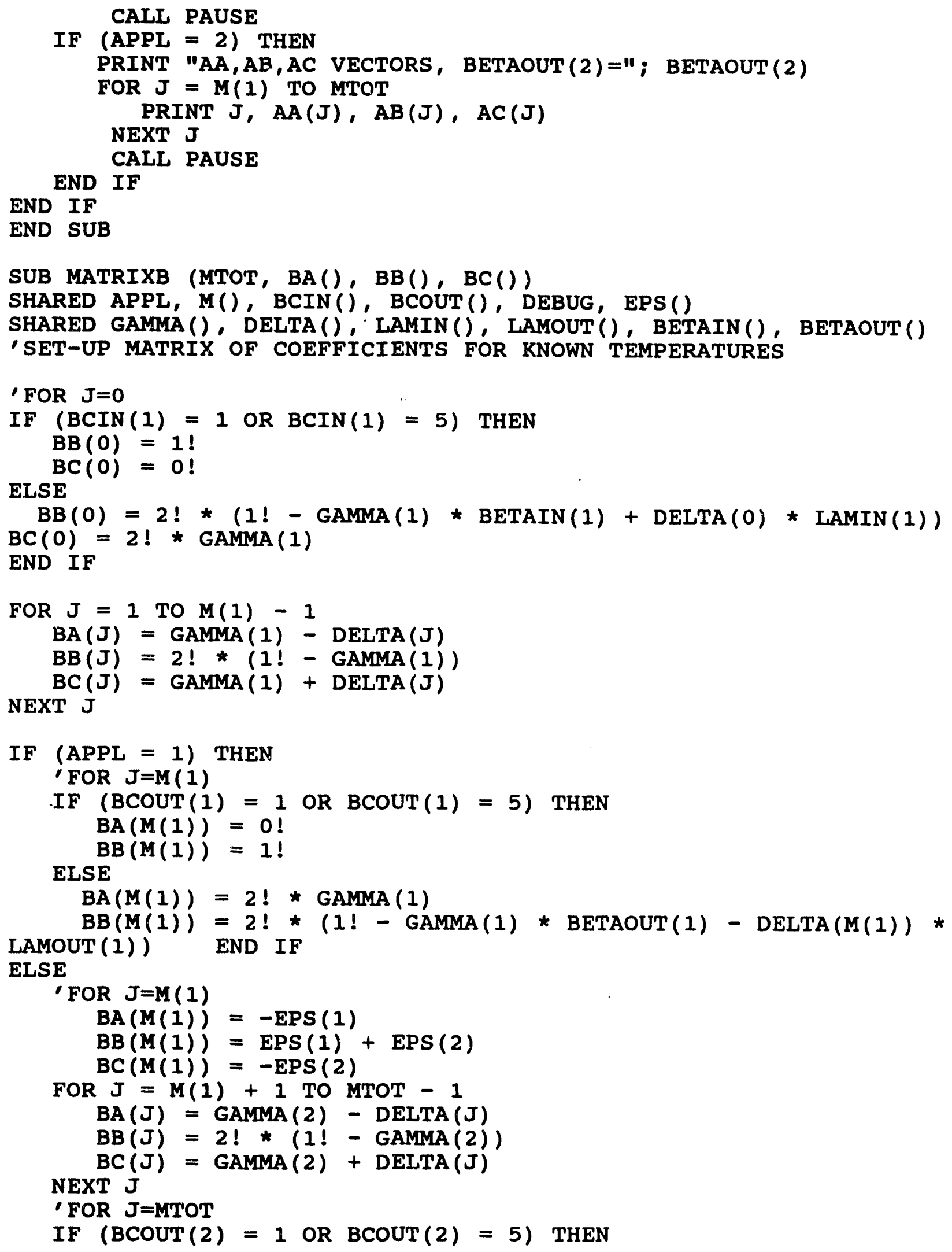




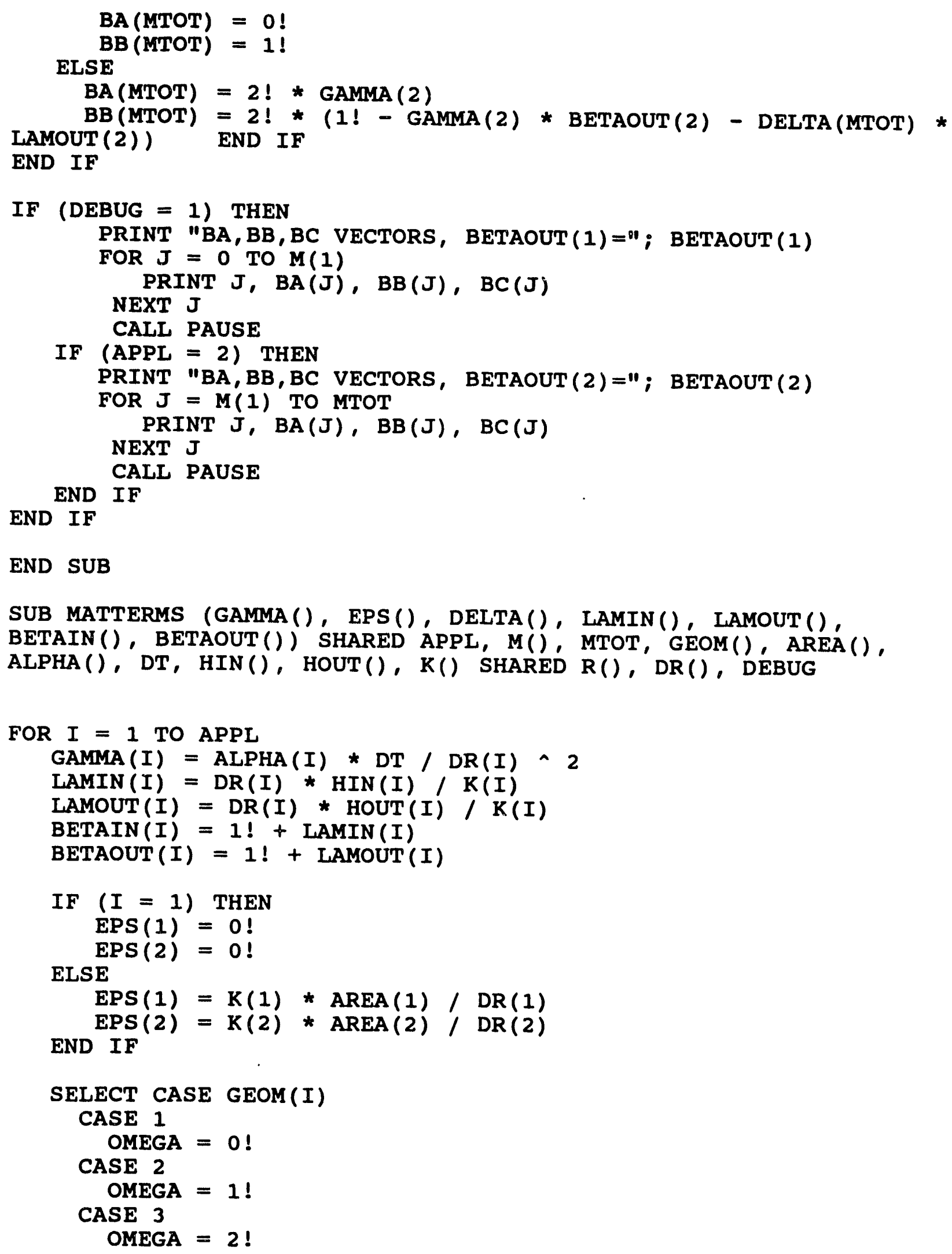


END SELECT

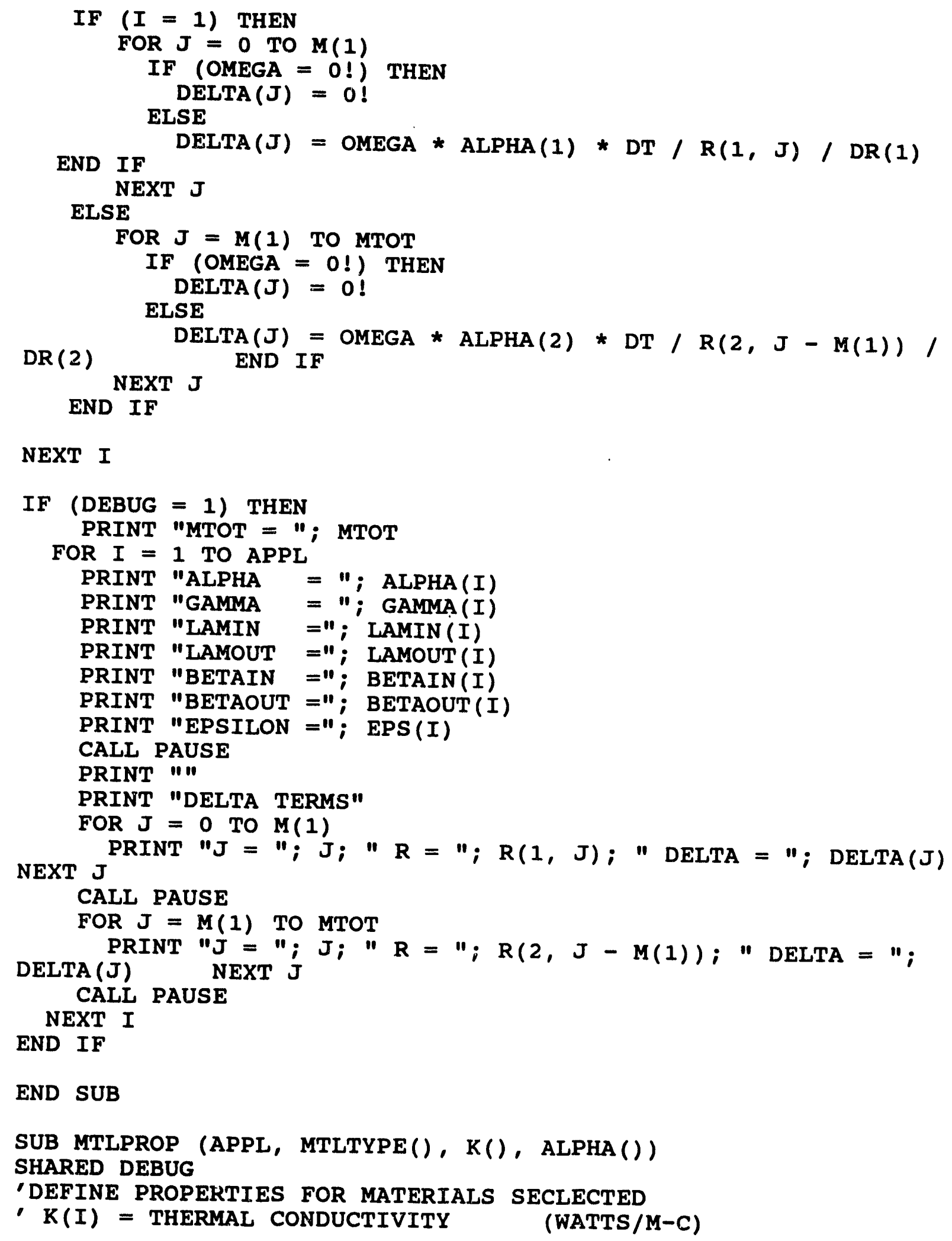


$\begin{array}{rll}\text { DENSITY }=\text { MATERIAL DENSITY } & (\mathrm{G} / \mathrm{CM} \wedge 3) \\ \text { HEATCAP }=\text { MATERIAL HEAT CAPACITY } & (\mathrm{CAL} / \mathrm{G}-\mathrm{C})\end{array}$

FOR $I=1$ TO APPL

SELECT CASE MTLTYPE(I)

CASE 1

$K(I)=16.26$

DENSITY $=7.83$

HEATCAP $=.12$

19.4 BTU/HR-FT^2-F/FT

$17.83 \mathrm{G} / \mathrm{CM}^{\wedge} 3$

'. $12 \mathrm{CAL} / \mathrm{G}-\mathrm{C}$ FOR STEEL

CASE 2

$K(I)=0$

DENSITY $=0$

HEATCAP $=0$

CASE 3 ' COPPER

$\mathrm{K}(\mathrm{I})=398$

DENSITY $=8.92$

HEATCAP $=.0924$

63.57 (G/MOLE)

CASE 4 'ALUMINUM

$15.44+0.001462 * \mathrm{~T}(\mathrm{~K}) \quad(\mathrm{CAL} / \mathrm{MOLE}-\mathrm{C})$

$K(I)=273$

DENSITY $=2.7$

26.97 (G/MOLE)

HEATCAP $=.214$

CASE 6

INPUT "INPUT THERMAL CONDUCTIVITY (WATTS/M-C) "; $K(I)$

INPUT "INPUT MATERIAL DENSITY (G/CM^3) "; DENSITY

INPUT "MATERIAL HEAT CAPACITY (CAL/G-C) "; HEATCAP

END SELECT

' CONVERT MATERIAL PROPERTIES

K FROM (WATTS/M-C) TO (WATTS/CM-C)

- HEATCAP FROM (CAL/G-C) TO (WATT-SEC/G-C)

- $100 \mathrm{CM} / \mathrm{M}$

, 0.23901 CAL/WATT-SEC

$\mathrm{K}(\mathrm{I})=\mathrm{K}(\mathrm{I}) / 100$ !

HEATCAP = HEATCAP / .23901

SELECT CASE MTLTYPE(I)

CASE 5

$\mathrm{K}(\mathrm{I})=1$ !

DENSITY $=1 !$

END SELECT

HEATCAP $=1$ !

' COMPUTE ALPHA = K/RHO-CP $\left(\mathrm{CM}^{\wedge} 2 / \mathrm{SEC}\right)$

$\operatorname{ALPHA}(I)=\mathrm{K}(\mathrm{I}) /$ DENSITY $/$ HEATCAP

IF (DEBUG $=1$ ) THEN

PRINT "MATERIAL "; I 


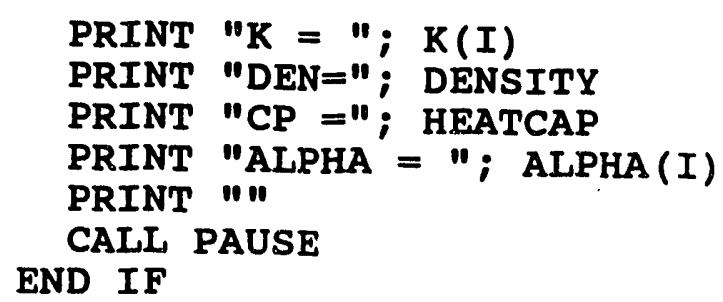




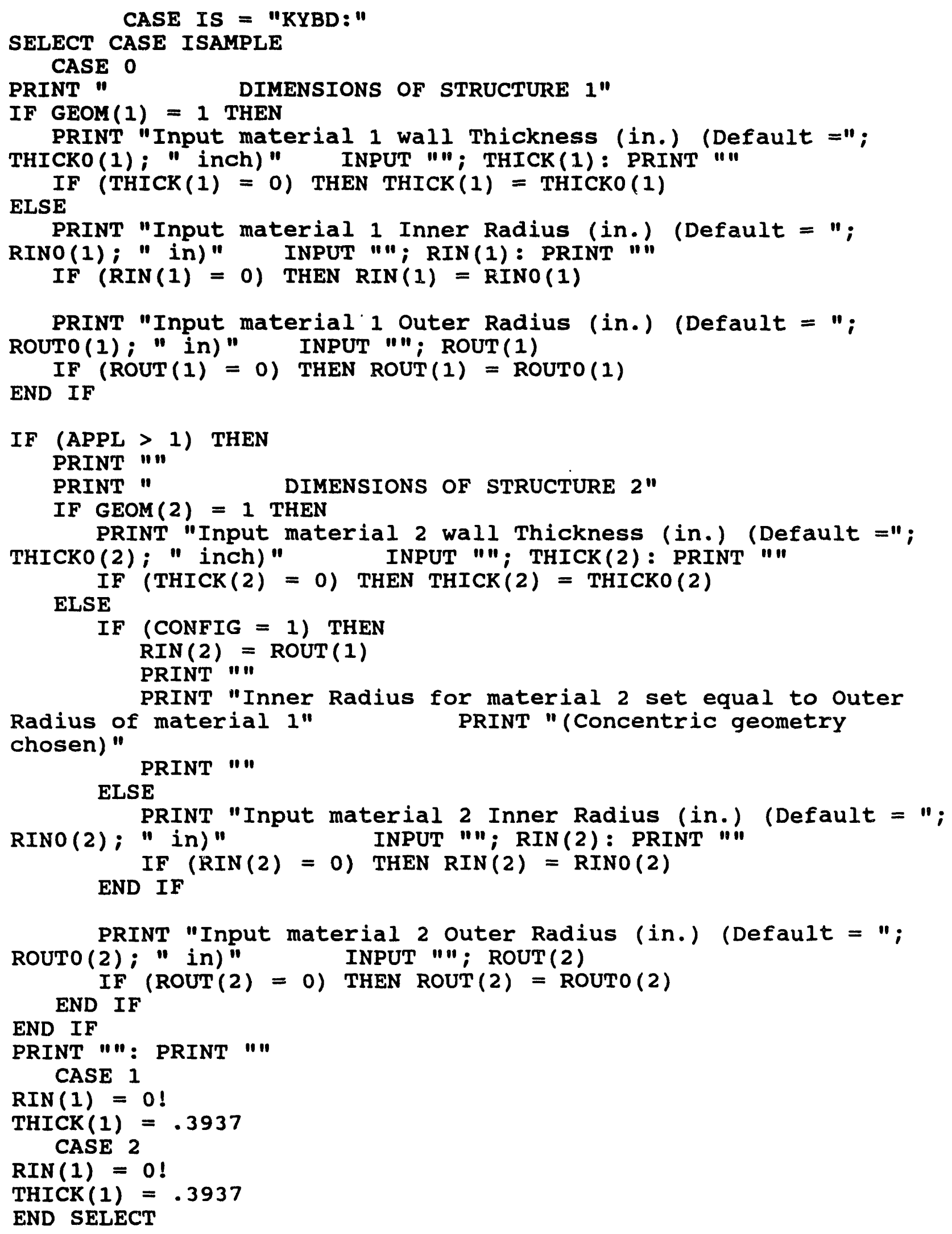


IF $(A B(0)=0)$ THEN PRINT "ERROR 1 IN SOLVE ROUTINE": END $\mathrm{BET}=\mathrm{AB}(0)$

$\operatorname{TNEW}(0)=D(0) /$ BET

FOR $J=1$ TO MTOT

WORK $(J)=A C(J-1) / B E T$

$B E T=A B(J)-A A(J) \star$ WORK (J)

IF $(B E T=0)$ THEN PRINT "ERROR 2 IN SOLVE ROUTINE": END

$\operatorname{TNEW}(J)=(D(J)-\operatorname{AA}(J) * \operatorname{TNEW}(J-1)) /$ BET

NEXT J

FOR $J=$ MTOT - 1 TO 0 STEP -1 NEXT $J$

$\operatorname{TNEW}(J)=\operatorname{TNEW}(J)-$ WORK $(J+1) * \operatorname{TNEW}(J+1)$

'NEXT I

IF (DEBUG $=2$ ) THEN

PRINT "TNEW VALUES"

FOR $J=0$ TO $M$

PRINT J, TNEW(J)

NEXT J

CALL PAUSE

IF (APPL $=2$ ) THEN

PRINT "TNEW VALUES"

FOR $J=0$ TO $M$

PRINT J, TNEW(J)

NEXT $J$

CALL PAUSE

END IF

END IF

END SUB

DEFINT J

SUB TIMEPARMS (DR(), ALPHA (), DT, N, TMAX)

SHARED ZINPUT\$, APPL

'subroutine for time step and totol time.

SELECT CASE ZINPUT\$

CASE IS = "KYBD:"

$\operatorname{DTMIN}=2 ! * \mathrm{DR}(1) \wedge 2 / \operatorname{ALPHA}(1)$

IF (APPL > 1) THEN

$\mathrm{DT}=2 ! * \mathrm{DR}(2) \wedge 2 / \operatorname{ALPHA}(2)$

IF (DT < DTMIN) THEN DTMIN = DT

END IF

CLS

PRINT "TIME STEP AND TOTAL TIME"

PRINT " "

PRINT "MAXIMUM ESTIMATED TIME STEP TO USE (SEC) = "; DTMIN

INPUT "Enter time step (sec) ", DT

IF $(D T=0)$ THEN DT $=$ DTMIN 


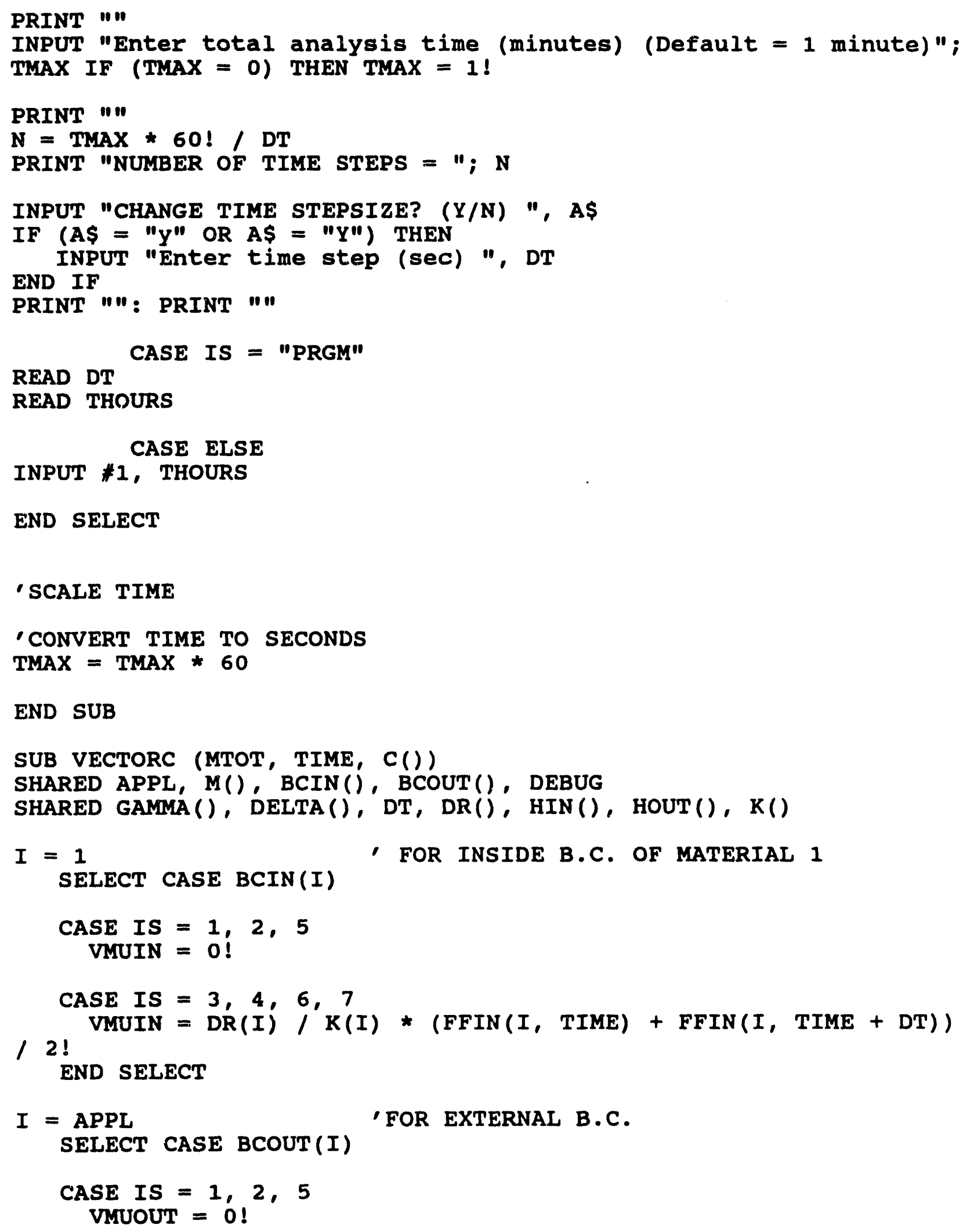




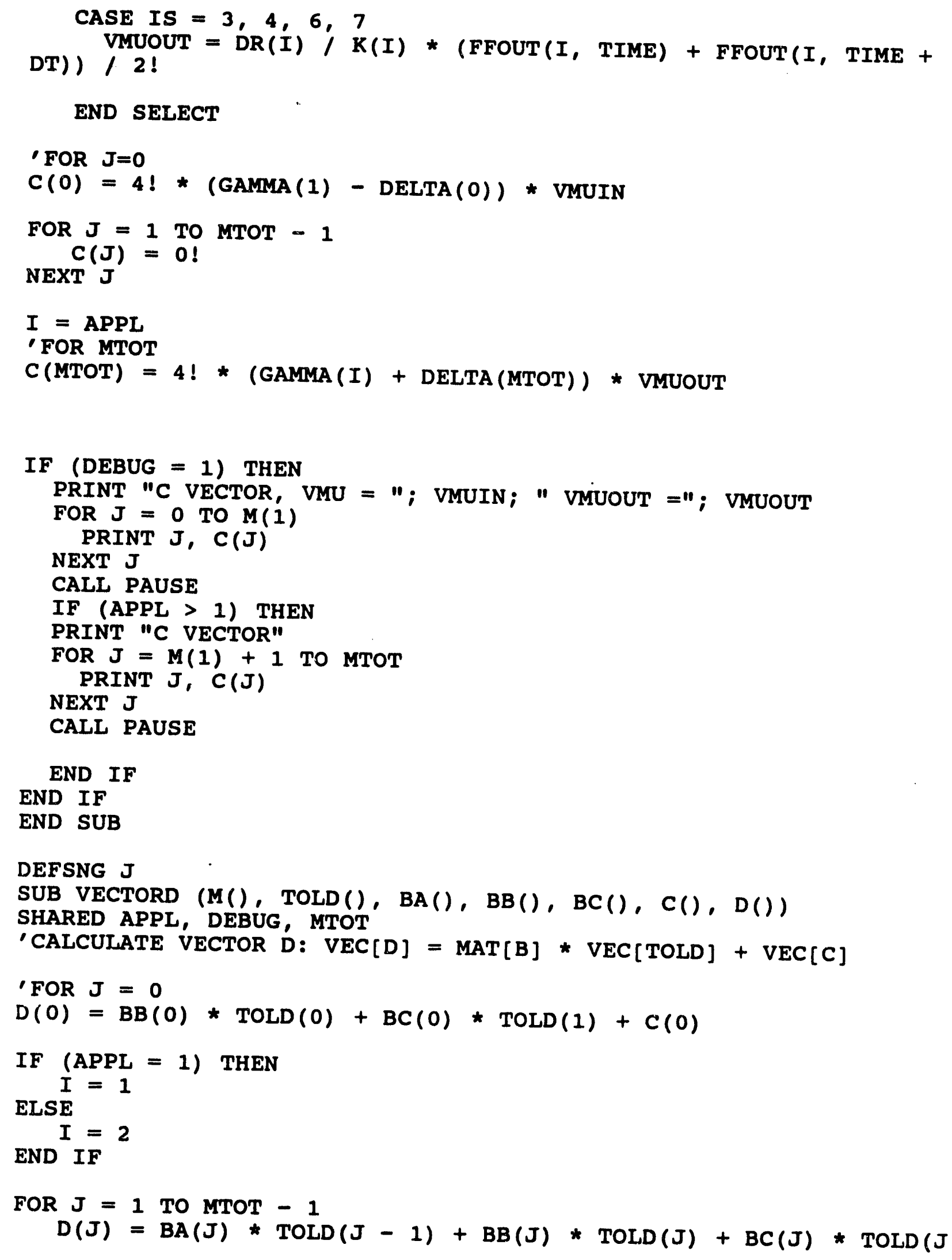




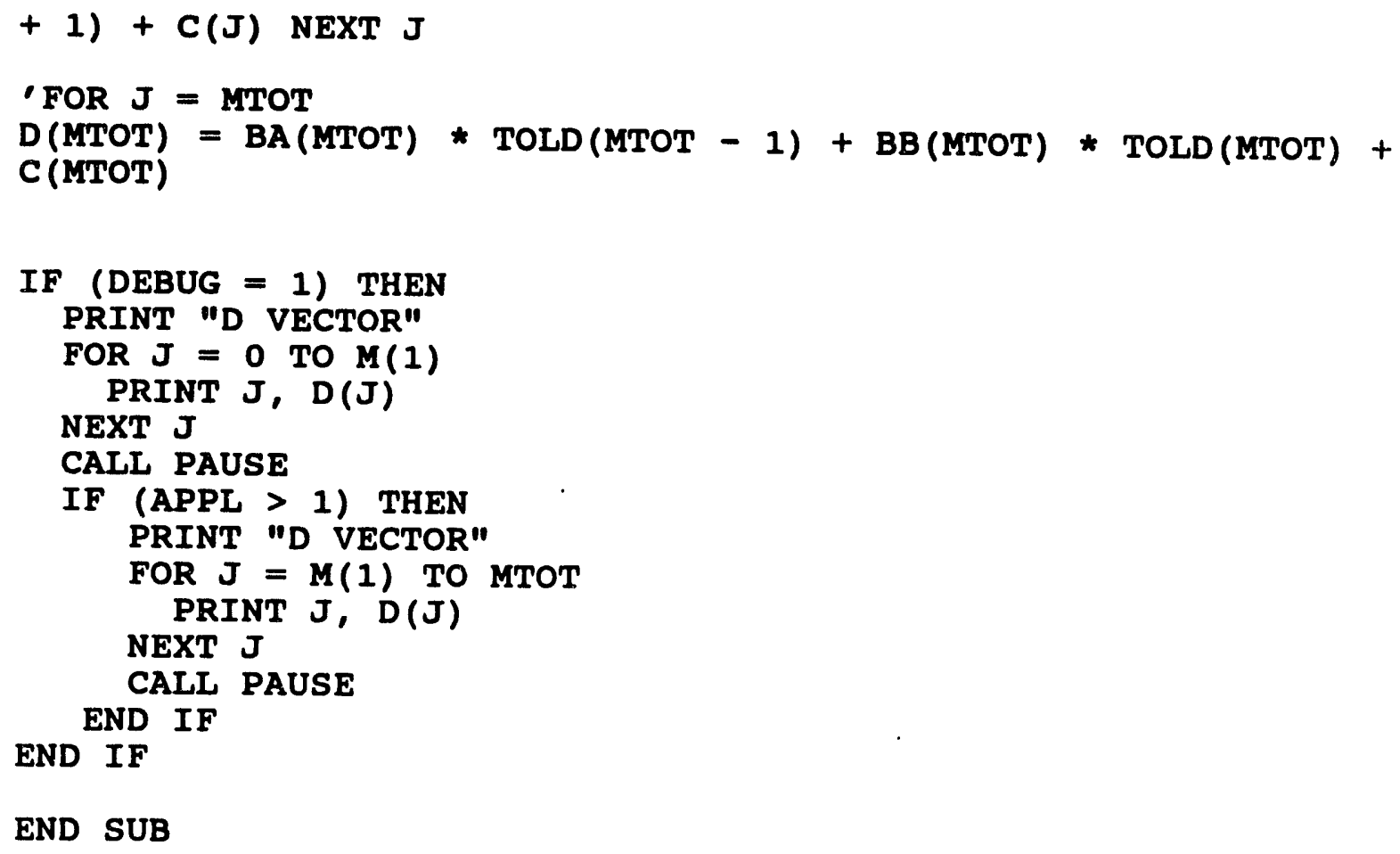

END SUB 


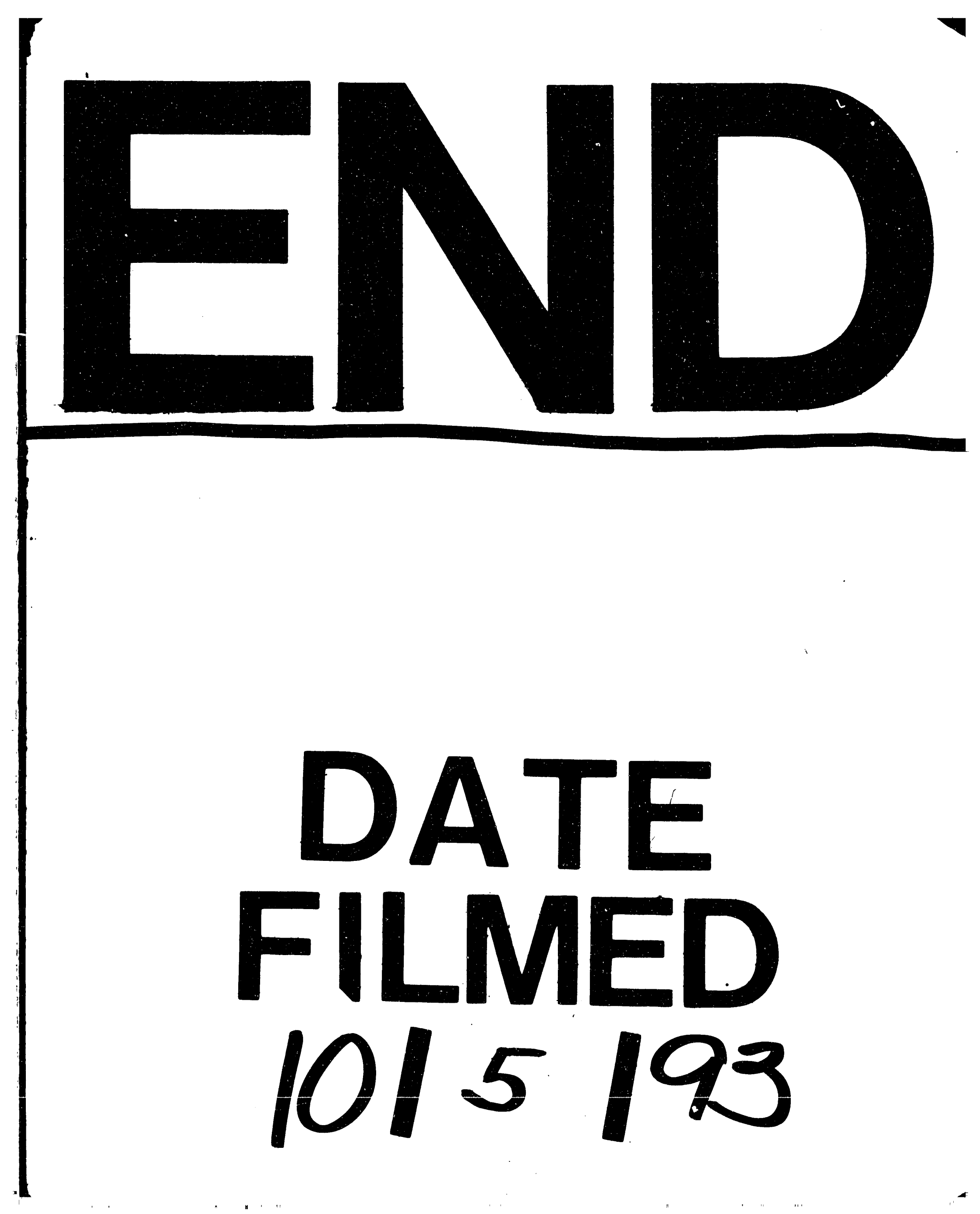


